ARTICLE

DOI: $10.1038 / s 41467-018-06911-w$

\title{
Cooperative mechanisms of oxygen vacancy stabilization and migration in the isolated tetrahedral anion Scheelite structure
}

\author{
Xiaoyan Yang ${ }^{1}$, Alberto J. Fernández-Carrión (1D ${ }^{2}$, Jiehua Wang ${ }^{1}$, Florence Porcher ${ }^{3}$, Franck Fayon², \\ Mathieu Allix (1) ${ }^{2} \&$ Xiaojun Kuang (1) ${ }^{1}$
}

Tetrahedral units can transport oxide anions via interstitial or vacancy defects owing to their great deformation and rotation flexibility. Compared with interstitial defects, vacancymediated oxide-ion conduction in tetrahedra-based structures is more difficult and occurs rarely. The isolated tetrahedral anion Scheelite structure has showed the advantage of conducting oxygen interstitials but oxygen vacancies can hardly be introduced into Scheelite to promote the oxide ion migration. Here we demonstrate that oxygen vacancies can be stabilized in the $\mathrm{BiVO}_{4}$ Scheelite structure through $\mathrm{Sr}^{2+}$ for $\mathrm{Bi}^{3+}$ substitution, leading to corner-sharing $\mathrm{V}_{2} \mathrm{O}_{7}$ tetrahedral dimers, and migrate via a cooperative mechanism involving $\mathrm{V}_{2} \mathrm{O}_{7}$-dimer breaking and reforming assisted by synergic rotation and deformation of neighboring $\mathrm{VO}_{4}$ tetrahedra. This finding reveals the ability of Scheelite structure to transport oxide ion through vacancies or interstitials, emphasizing the possibility to develop oxide-ion conductors with parallel vacancy and interstitial doping strategies within the same tetrahedra-based structure type.

\footnotetext{
${ }^{1}$ MOE Key Laboratory of New Processing Technology for Nonferrous Metals and Materials, Guangxi University Key Laboratory of Nonferrous Metal Oxide Electronic Functional Materials and Devices, College of Materials Science and Engineering, Guilin University of Technology, Guilin, Guangxi 541004, People's Republic of China. ${ }^{2}$ CNRS, CEMHTI UPR3079, Univ. Orléans, 45071 Orléans, France. ${ }^{3}$ Laboratoire Léon Brillouin, CEA Saclay, 91191 Gif Sur Yvette, France. These authors contributed equally: Xiaoyan Yang, Alberto J. Fernández-Carrión. Correspondence and requests for materials should be addressed to M.A. (email: mathieu.allix@cnrs-orleans.fr) or to X.K. (email: kuangxj@glut.edu.cn)
} 
esearch for solid oxide fuel cells with lower operating temperature has stimulated the discovery of new oxide ion conductors and the understanding of the mechanisms driving the stabilization of oxide anionic defects and oxide ion mobility ${ }^{1-6}$. Recently, structure types containing tetrahedral moieties have received growing attention as new oxide ion conductor candidates, owing to the deformation and rotation flexibility of tetrahedral units which facilitates the stabilization and transportation of oxygen interstitial or vacancy defects ${ }^{1,3,7}$. Oxygen interstitials often appear as charge carriers inducing oxide ion conduction in tetrahedra-based structures ${ }^{1,7-9}$. Variable coordination geometry of the cations in the tetrahedral centers is important for stabilizing interstitial defects, allowing incorporation of extra oxygen atoms into the bonding environments of tetrahedral cations ${ }^{1,6-9}$. In low-dimensional structures, the ease of deformation and rotation of tetrahedral units allows for the accommodation and transportation of the interstitial defects. For example, $\mathrm{La}_{10-x}\left(\mathrm{MO}_{4}\right)_{6} \mathrm{O}_{3-1.5 x}(\mathrm{M}=\mathrm{Si}, \mathrm{Ge})$-based apatites ${ }^{8,10}$ and $\mathrm{La}_{2} \mathrm{Mo}_{2} \mathrm{O}_{9}$-based $(\mathrm{LaMOX})^{2,6}$ oxide ion conductors adopt isolated tetrahedral anion structures, and $L n_{1+x} A_{1-x} \mathrm{Ga}_{3} \mathrm{O}_{7+0.5 x}$ $(\mathrm{Ln}=\mathrm{La}, \mathrm{Gd}, \mathrm{Eu}, \mathrm{Tb}, A=\mathrm{Ca}, \mathrm{Sr}, \mathrm{Ba})$ gallate melilites exhibit a two-dimensional (2D) interstitial oxide ion conductivity in the layered tetrahedral network ${ }^{1,11-15}$.

Compared with oxygen interstitials, vacancy-mediated oxide ion conduction occurs rarely in tetrahedra-based structures. The identification of such tetrahedral structures with the ability to accommodate oxygen vacancies to facilitate oxide-on migration is important to the development of new oxide ion conductors. An example of oxygen vacancy accommodation in tetrahedra-based structures is the formation of bridging oxygen atoms between neighboring tetrahedra, which maintains tetrahedral coordination instead of producing unstable three-fold coordination geometry ${ }^{3}$. In such a case, the tetrahedra-based structures must possess sufficient rotation and deformation flexibility to enable a cornersharing formation process for accommodating oxygen vacancy defects, as well as breaking of the corner-sharing structure for the oxygen vacancy migration. This mechanism was demonstrated in the case of the $\mathrm{La}_{1-x} \mathrm{Ba}_{1+x} \mathrm{GaO}_{4-0.5 x}$ isolated tetrahedral anion structure $^{3}$, one of the few oxygen vacancy conducting materials based on purely tetrahedral moieties. In $\mathrm{La}_{1-x} \mathrm{Ba}_{1+x} \mathrm{GaO}_{4-0.5 x}$, the presence of oxygen vacancies leads to the formation of corner-sharing $\mathrm{Ga}_{2} \mathrm{O}_{7}$ units and oxygen vacancies migrate according to a cooperative mechanism involving continuous breaking and reforming of $\mathrm{Ga}_{2} \mathrm{O}_{7}$ dimers enabled by the rotation and deformation of $\mathrm{Ga}_{2} \mathrm{O}_{7}$ and $\mathrm{GaO}_{4}$ units ${ }^{3}$.

Apart from tetrahedra-based structures, the advantage of tetrahedral units on transporting oxide anions has also been demonstrated in the traditional fluorite-based superstructures, for example, $\mathrm{Bi}_{1-x} \mathrm{~V}_{x} \mathrm{O}_{1.5+x}$ system containing isolated $\mathrm{VO}_{4}$ tetrahedra diluted in the fluorite lattice, where $\mathrm{V}^{5+}$ cations have variable coordination numbers (from 4 to 6$)^{16,17}$. The $x=$ 0.087-0.095 composition range demonstrates high oxide ion conductivity (up to $0.04 \mathrm{~S} \mathrm{~cm}^{-1}$ at $500^{\circ} \mathrm{C}$ ) and adopts a pseudocubic $3 \times 3 \times 3$ fluorite superstructure with $\mathrm{VO}_{4}$ tetrahedra apart from each other by $\sim 6.7 \AA$ without interaction between them ${ }^{16}$. In this superstructure, ab initio molecular dynamic (MD) simulations demonstrated that the isolated $\mathrm{VO}_{4}$ tetrahedra participate to transport oxide anions, which migrate by hopping among the vacancies in $\mathrm{Bi}-\mathrm{O}$ fluorite slabs and are transported by the diluted $\mathrm{VO}_{4}$ tetrahedra through a process of continuous formation, rotation, and breaking up of highly coordinated $\mathrm{VO}_{4+n}$ polyhedra ${ }^{16}$. Increase of the $\mathrm{V}^{5+}$ content in $\mathrm{Bi}_{1-x} \mathrm{~V}_{x} \mathrm{O}_{1.5+x}$ leads to closer $\mathrm{VO}_{4}$ tetrahedra, which constrains their rotation and thus reduces the oxide ion mobility, as revealed in $\mathrm{Bi}_{46} \mathrm{~V}_{8} \mathrm{O}_{89}(x=$ $0.148)^{17}$. Further increase of the $\mathrm{V}$ content to $x=0.5$ (i.e., to $\mathrm{BiVO}_{4}$ ) results in a Scheelite structure (Fig. 1), which is a variant
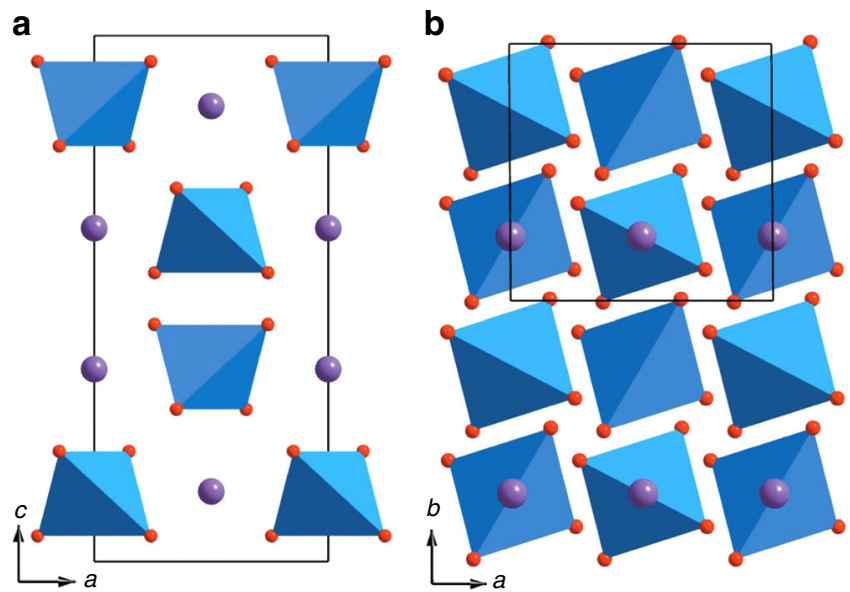

Fig. 1 The $\mathrm{BiVO}_{4}$ Scheelite structure. a [010] and b [001] projections. The violet and red spheres denote $\mathrm{Bi}$ and $\mathrm{O}$ atoms, respectively. The $\mathrm{V}$ atoms (not shown) are at the center of the tetrahedra

of the fluorite structure but composed of isolated $\mathrm{VO}_{4}$ tetrahedra with all the oxygen anions bonded with $\mathrm{V}^{5+}$ cations. $\mathrm{BiVO}_{4}$ adopts a distorted Scheelite structure with monoclinic symmetry at ambient temperature and transforms to tetragonal Scheelite phase at $250{ }^{\circ} \mathrm{C}^{18}$. Even though oxide ion conductivity was reported in the $\mathrm{BiVO}_{4}$ Scheelite ${ }^{19,20}$, no further interest was devoted to the oxide ion conduction mechanism in $\mathrm{BiVO}_{4}$-based materials, which instead have received considerable interest for their photocatalytic properties ${ }^{21,22}$.

Scheelite-type materials have demonstrated interstitial oxide ion conduction, for example, donor-doped $\mathrm{La}_{x} \mathrm{~Pb}_{1-x} \mathrm{WO}_{4+0.5 x}{ }^{23}$ and mixed-valent $\mathrm{CeNbO}_{4+x}{ }^{7,24}$ materials, in which the oxygen interstitials are incorporated into the tetrahedral units resulting in a linked polyhedral network. Compared with the interstitial oxide ion conduction, very little attention has been paid on the oxygen vacancy conduction mechanism in Scheelites and the ability of the structure to accommodate oxygen vacancies allowing the oxide ion migration remains so far unclear. Unraveling the local structure surrounding the oxygen vacancies and elucidating the oxygen vacancy migration mechanism in the acceptor-doped Scheelites are key for the development of new oxide ion conductors with improved properties from the common Scheelite family and other related systems.

In this study, we demonstrate the creation, stabilization, and migration of oxygen vacancies in the $\mathrm{BiVO}_{4}$ Scheelite structure through substitution of $\mathrm{Sr}^{2+}$ for $\mathrm{Bi}^{3+}$. Multiple complementary techniques, including synchrotron powder diffraction and neutron powder diffraction (SPD and NPD), solid-state ${ }^{51} \mathrm{~V}$ nuclear magnetic resonance (NMR) spectroscopy, density functional theory (DFT) calculations and interatomic-potential-based $\mathrm{MD}$ simulations, evidence that the oxygen vacancies in $\mathrm{Bi}_{1-x} \mathrm{Sr}_{x}$ $\mathrm{VO}_{4-0.5 x}$ are accommodated via formation of corner-sharing tetrahedral $\mathrm{V}_{2} \mathrm{O}_{7}$ dimers and the oxygen vacancy migration in the Scheelite structure involves $\mathrm{V}_{2} \mathrm{O}_{7}$-dimer breaking and reforming process assisted by cooperative rotations and deformations of isolated neighboring tetrahedra.

\section{Results}

$\mathbf{B i}_{1-x} \mathbf{S r}_{x} \mathbf{V O}_{4-\mathbf{0 . 5 x}}$ solid solution. Initially, $\mathrm{Bi}_{1-x} \mathrm{Sr}_{x} \mathrm{VO}_{4-0.5 x}$ samples were prepared by conventional solid-state (CSS) method. However, $\mathrm{Bi}_{1-x} \mathrm{Sr}_{x} \mathrm{VO}_{4-0.5 x}(x=0.05-0.1)$ samples synthesized by the CSS route form a mixture of monoclinic $\left(m-\mathrm{Bi}_{1-x} \mathrm{Sr}_{x}\right.$ $\left.\mathrm{VO}_{4-0.5 x}\right)$ and tetragonal $\left(t-\mathrm{Bi}_{1-x} \mathrm{Sr}_{x} \mathrm{VO}_{4-0.5 x}\right)$ Scheelite polymorphs with the same composition, as revealed by $\mathrm{X}$-ray 
a

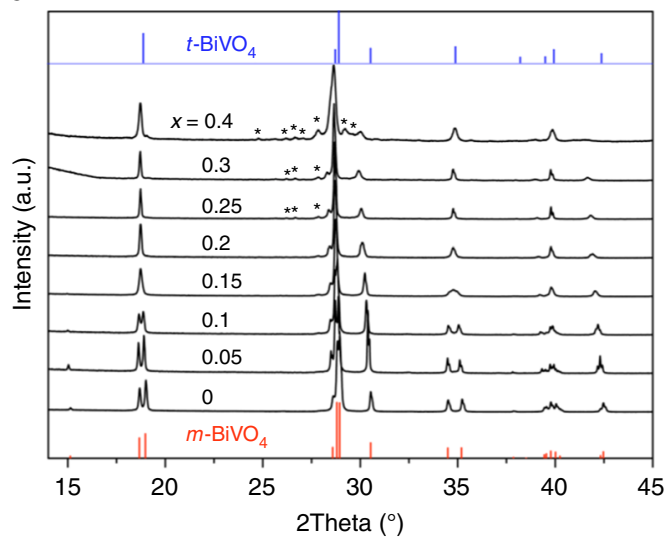

b

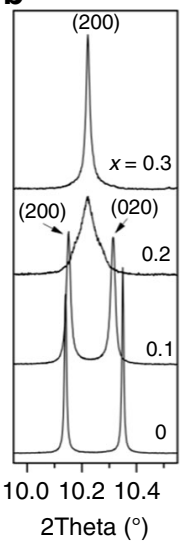

C

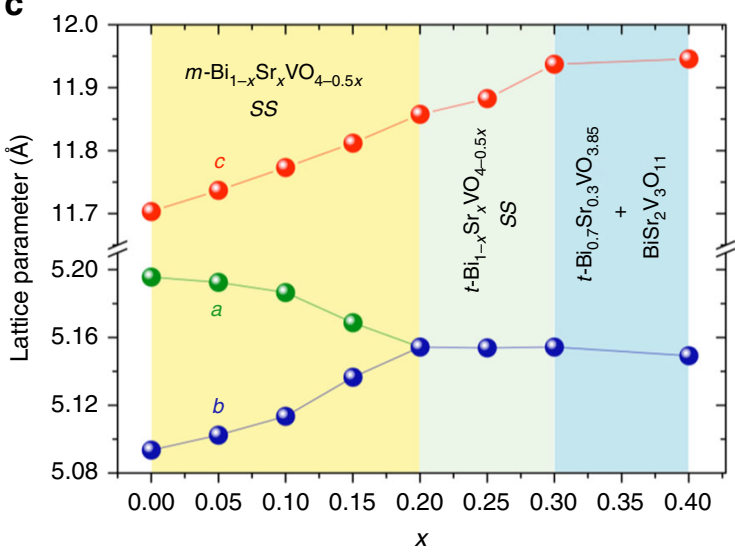

Fig. 2 The solid solubility limit of $\mathrm{Bi}_{1-x} \mathrm{Sr}_{x} \mathrm{VO}_{4-0.5 x}$ a Ambient temperature laboratory XRD data of $\mathrm{Bi}_{1-x} \mathrm{Sr}_{x} \mathrm{VO}_{4-0.5 x}$ samples obtained by $A D L$ synthesis. The red (bottom) and blue (top) vertical marks indicate the peak positions and relative intensities of monoclinic (no. 01-044-0081) and tetragonal (no. 01075-2481) $\mathrm{BiVO}_{4}$ from the ICDD database, respectively. Asterisk marks indicate $\mathrm{BiSr}_{2} \mathrm{~V}_{3} \mathrm{O}_{11}$ secondary phase. $\mathbf{b}$ Merging of the monoclinic (200) and (020) reflections into single (200) reflection in the tetragonal phase from high-resolution SPD data. c Refined cell parameters of $\mathrm{Bi}_{1-x} \mathrm{Sr}_{x} \mathrm{VO}_{4-0.5 x}$ solid solution (SS). The error bars are lying behind the symbols

diffraction (XRD) data analysis (Supplementary Note 1 and Supplementary Figs. 1-3). The limit of the solid solution, as $x=0.1$ for the CSS synthesis, can be extended significantly to $x=0.3$ (Fig. 2) via direct crystallization from the melt using aerodynamic levitation (ADL) coupled to laser heating (Supplementary Fig. 4). The ADL method provides great homogenization during the melting step and allows the stabilization of the monoclinic polymorph when the sample crystallizes during rapid cooling. Energy X-ray dispersive spectroscopy (EDS) elementary analyses performed on scanning electron microscopy (SEM) indicate highly compositional homogeneity in the Scheelite phase (Supplementary Fig. 5 and Supplementary Table 1) and neither SEM/transmission electron microscopy (TEM) nor XRD detect any remaining glass in the samples synthesized by the ADL method. The sole monoclinic polymorph is maintained up to $x=0.15$ and the $x=0.2$ sample forms a tetragonal phase (Fig. 2 a-b). These results are in good agreement with the compositional dependency of the cell parameters (Fig. 2c and Supplementary Fig. 6). The unit cell volume expands with the $\mathrm{Sr}^{2+}$ substitution for $\mathrm{Bi}^{3+}$, which is consistent with the larger $\mathrm{Sr}^{2+}$ ionic radius (the ionic radii of 8-coordinated $\mathrm{Sr}^{2+}$ and $\mathrm{Bi}^{3+}$ are $1.26 \AA$ and $1.17 \AA$, respectively $)^{25}$. The contraction of the $a$-axis and expansion of the $b$-axis are observed for $m-\mathrm{Bi}_{1-x} \mathrm{Sr}_{x} \mathrm{VO}_{4-0.5 x}$, which result in equal $a$ an $b$ axes when $x \geq 0.2$. Therefore, the $\mathrm{Sr}^{2+}$ substitution for $\mathrm{Bi}^{3+}$ appears to stabilize the tetragonal Scheelite phase. This observation is supported by variable-temperature XRD (VT-XRD) experiments performed on $\mathrm{Bi}_{0.9} \mathrm{Sr}_{0.1} \mathrm{VO}_{3.95}$ and the pristine $\mathrm{BiVO}_{4}$ samples, showing that upon heating the monoclinic-to-tetragonal phase transition temperature decreases from $\sim 250^{\circ} \mathrm{C}$ for the parent $\mathrm{BiVO}_{4}$ to $\sim 150^{\circ} \mathrm{C}$ for the $\mathrm{Sr}$ substituted composition $x=0.1$ (Supplementary Fig. 7). Compositions $0.25 \leq x \leq 0.4$ also exhibit several extra reflections corresponding to the $\mathrm{BiSr}_{2} \mathrm{~V}_{3} \mathrm{O}_{11}$ secondary phase ${ }^{26}$ (its content quantified through two-phase Rietveld refinement is $\sim 12-15 \mathrm{wt} \%$ for $x=0.25-0.3$, and then dramatically increases to $\sim 36 \mathrm{wt} \%$ for $x=0.4$, see Fig. $2 \mathrm{a}$ ) and are related to the complex sample synthesis. For $0.2 \leq x \leq 0.3$, the $a$ and $b$ unit cell parameters of $t$ - $\mathrm{Bi}_{1-x} \mathrm{Sr}_{x} \mathrm{VO}_{4-0.5 x}$ remain constant, while the $c$ lattice parameter linearly increases up to $30 \% \mathrm{Sr}$ substitution (Fig. 2c). Beyond $x=0.3$, the lattice parameters remain unchanged, indicating the limit of the solid solution at $x=0.3$ within tetragonal phase using the ADL approach. Owing to the ability of the ADL route to enable the synthesis of homogenous single-phase $\mathrm{Bi}_{1-x} \mathrm{Sr}_{x} \mathrm{VO}_{4-0.5 x}$ samples, the following structural and property characterizations will focus on the samples obtained by ADL method (unless peculiar specification).

Rietveld analysis. Rietveld refinements of SPD and NPD data of $\mathrm{Bi}_{0.9} \mathrm{Sr}_{0.1} \mathrm{VO}_{3.95}$ (Supplementary Fig. 8) were performed in order to elucidate how the acceptor $\mathrm{Sr}^{2+}$ substitution for $\mathrm{Bi}^{3+}$ and the resultant oxygen vacancies affect the $\mathrm{BiVO}_{4}$ Scheelite structure. The monoclinic $\mathrm{BiVO}_{4}$ Scheelite model ${ }^{27}$ described in the $I 2 / b$ space group, which contains one $\mathrm{Bi} / \mathrm{Sr}$, one $\mathrm{V}$ and two $\mathrm{O}$ crystallographic sites, was used in the refinement. First, the SPD data were refined and the resulting structural model (Supplementary Table 2) obtained from the SPD data refinement was transferred to NPD data refinement, in which all positional parameters for $\mathrm{V}$ atoms were fixed at those obtained from the SPD data refinement given that neutrons are hardly scattered by vanadium nuclei ${ }^{28}$. The refinement led to a $\mathrm{Bi}_{0.893(2)} \mathrm{Sr}_{0.107(2)} \mathrm{VO}_{3.918(6)}$ composition, confirming the $\mathrm{Bi}_{0.9} \mathrm{Sr}_{0.1}$ composition and the presence of oxygen vacancies. The magnitudes of refined anisotropic atomic displacement parameters (ADPs) for the $\mathrm{Bi} / \mathrm{Sr}$ and oxygen sites (Supplementary Table 3) and their thermal-ellipsoid shapes (Supplementary Fig. 9) indicate that oxygen vacancies induce positional disorder.

The difference Fourier map showed no residual scattering density that could be attributed to the presences of new crystallographic sites generated from the relaxation of atoms surrounding the vacancy defects. Therefore, the structural variation induced by the oxygen vacancy in the Sr-substituted $\mathrm{BiVO}_{4}$ cannot be further characterized here by the SPD or NPD techniques, which provide solely a long-range averaged model. The structural defects probably occur locally with a diversity of possible configurations, which, alternatively, solid-state NMR spectroscopy is a powerful tool to probe on the atomic scale.

${ }^{51}$ V NMR spectra and DFT calculations. To obtain insight about local structural modifications occurring upon $\mathrm{Sr}^{2+}$ substitution for $\mathrm{Bi}^{3+},{ }^{51} \mathrm{~V}$ solid-state magic-angle spinning (MAS) NMR spectroscopy was employed as a sensitive probe of local chemical environment variation, owing to the large ${ }^{51} \mathrm{~V}$ chemical shift range and moderate quadrupolar interaction ${ }^{29-31}$. Indeed, every $\mathrm{VO}_{4}$ unit is surrounded by eight $\mathrm{Bi}$ atoms in the parent Scheelite structure and accommodation for oxygen vacancies upon $\mathrm{Sr}^{2+}$ 
for $\mathrm{Bi}^{3+}$ substitution should lead to significant modifications of the ${ }^{51} \mathrm{~V}$ chemical shift and quadrupolar coupling parameters.

Figure 3 shows the ${ }^{51} \mathrm{~V}$ MAS NMR spectra of $\mathrm{Bi}_{1-x} \mathrm{Sr}_{x} \mathrm{VO}_{4-0.5 x}$ $(x=0-0.2)$ samples, recorded at very high magnetic field $(20.0 \mathrm{~T})$ and very high spinning frequency $(60 \mathrm{kHz})$. The ${ }^{51} \mathrm{~V}(7 / 2$-spin nucleus) MAS spectrum of parent $\mathrm{BiVO}_{4}$ exhibits a single intense central-transition (CT) resonance and spinning sideband manifolds from the corresponding six satellite transitions affected by the firstorder quadrupolar interaction, thereby demonstrating the presence of a single $\mathrm{V}$ environment, as expected. The ${ }^{51} \mathrm{~V}$ isotropic chemical shift $\left(\delta_{\text {ISO }}\right)$, quadrupolar coupling, and chemical shift anisotropy (CSA) parameters determined from the least-squares fitting of the high-field spectrum are supported by measurements performed at lower magnetic field and spinning rate (Supplementary Figs. 1011 ), and are in good agreement with previous studies ${ }^{30}$. The ${ }^{51} \mathrm{~V}$ MAS spectra of Sr-substituted samples show that the $\mathrm{Sr}^{2+}$ substitution for $\mathrm{Bi}^{3+}$ in the Scheelite structure leads to the appearance of several broad ${ }^{51} \mathrm{~V}$ resonances, the intensities of which increase with the $\mathrm{Sr}$ content. The peak characteristic of $\mathrm{BiVO}_{4}$-like local environment (at $-421 \mathrm{ppm}$ ) broadens and slightly shifts toward higher frequencies for increased $\mathrm{Sr} / \mathrm{Bi}$ ratios. For all observed CT peaks, the linewidths (expressed in $\mathrm{Hz}$ ) increase proportionally with the applied field (Supplementary Figs. 10-11), and strongly spread along the isotropic chemical shift distribution axis of $2 \mathrm{D}{ }^{51} \mathrm{~V}$ MQMAS spectra (Supplementary Fig. 12). This demonstrates that the line broadenings are mainly due to distributions of the ${ }^{51} \mathrm{~V}$ isotropic chemical shift, reflecting strong positional disorder of the local chemical structures associated with each peak. Quantitative ${ }^{51} \mathrm{~V}$ MAS spectra were simulated considering four CT peaks of Gaussian shapes and the associated spinning sidebands manifolds from all satellite transitions. The ${ }^{51} \mathrm{~V}$ average isotropic chemical shift and quadrupolar coupling parameters of each contribution were determined from the least-squares fits of the spectra recorded at two magnetic fields. Due to the overlap between broad contributions, the weak effect of CSA on the intensities of the satellite-transition spinning sidebands was neglected (note that for pure $\mathrm{BiVO}_{4}$, neglecting the CSA effect only leads to $<0.5 \%$ decrease of the quadrupolar coupling constants $\left.\left|C_{\mathrm{Q}}\right|\right)$. The ${ }^{51} \mathrm{~V} \delta_{\mathrm{ISO}},\left|C_{\mathrm{Q}}\right|$, biaxiality parameters $\left(\eta_{\mathrm{Q}}\right)$, and relative intensities of the four contributions corresponding to four types of vanadium local

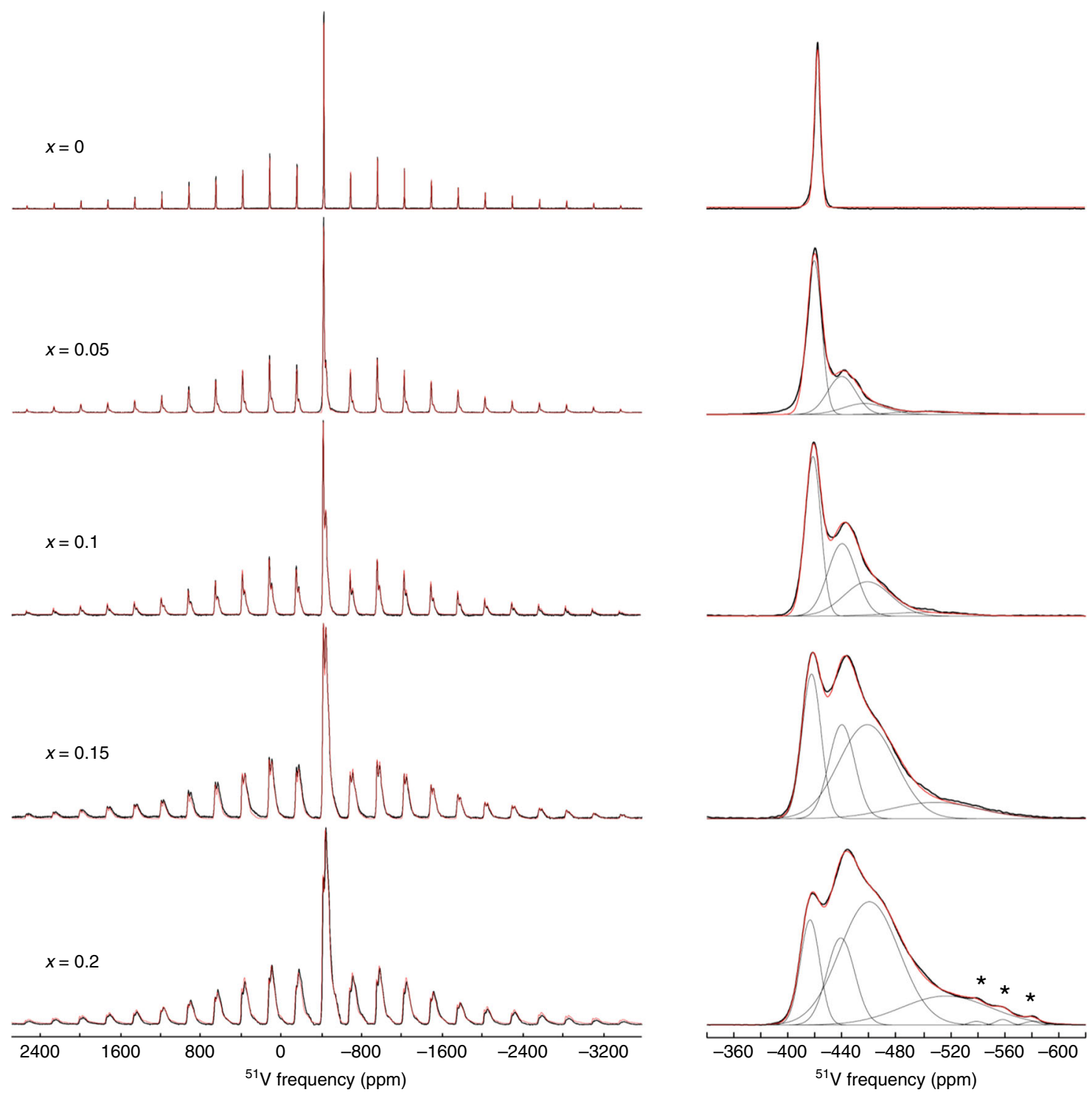

Fig. $3{ }^{51} \mathrm{~V}$ MAS NMR spectra of $\mathrm{Bi}_{1-x} \mathrm{Sr}_{x} \mathrm{VO}_{4-0.5 x}$. (Left) Quantitative ${ }^{51} \mathrm{~V}$ MAS spectra recorded at $20.0 \mathrm{~T}$ with a spinning frequency of $60 \mathrm{kHz}$ (black) and their corresponding best fits (red). (Right) expansion of the central-transition region. The four distinct contributions are shown as thin black lines and asterisks mark impurities (probably $\mathrm{BiSr}_{2} \mathrm{~V}_{3} \mathrm{O}_{11}$ ) 
Table $1^{51} \mathrm{~V}$ NMR parameters

\begin{tabular}{|c|c|c|c|c|c|c|c|c|c|}
\hline Compound & Unit & & $\delta_{\text {ISO }}(\mathrm{ppm})$ & $\begin{array}{l}\left|C_{Q}\right| \\
(M H z)\end{array}$ & $\eta_{\mathbf{Q}}$ & $\delta_{\mathrm{CSA}}(\mathrm{ppm})$ & $\eta_{\text {CSA }}$ & $\begin{array}{l}\sigma_{\mathrm{ISO}} \\
(\mathrm{ppm})\end{array}$ & $\alpha, \beta, \gamma\left(^{\circ}\right)$ \\
\hline \multirow[t]{3}{*}{$\mathrm{a} \mathrm{BiVO}_{4}$} & $\mathrm{VO}_{4}(\mathrm{OSr}, 8 \mathrm{Bi})$ & Exp. & $-420.7(5)$ & $4.97(2)$ & $0.38(5)$ & $89(5)$ & $0.3(1)$ & & \multirow{12}{*}{$\begin{array}{l}80(20) \\
0,0 \\
26.5,0,0\end{array}$} \\
\hline & & $\mathrm{DFT}$ & -439 & 5.165 & 0.19 & 62.4 & 0.41 & -1527 & \\
\hline & Experimental & $\delta_{\text {Iso }}(\mathrm{ppm})$ & $\left|C_{\mathbf{Q}}\right|(\mathbf{M H z})$ & $\eta_{\mathbf{Q}}$ & $\begin{array}{l}\text { FWHM } \\
\text { (ppm) }\end{array}$ & $I(\% \pm 5)$ & & & \\
\hline \multirow[t]{5}{*}{ b $\mathrm{Sr}_{0.1} \mathrm{Bi}_{0.9} \mathrm{VO}_{3.95}$} & $\mathrm{VO}_{4}(\mathrm{OSr}, 8 \mathrm{Bi})$ & $-417(1)$ & $4.75(5)$ & $0.4(1)$ & $14(1)$ & 37 & & & \\
\hline & $\mathrm{VO}_{4}(1 \mathrm{Sr}, 7 \mathrm{Bi})$ & $-439(3)$ & $4.5(1)$ & $0.5(1)$ & $25(1)$ & 33 & & & \\
\hline & $\mathrm{VO}_{4}(2 \mathrm{Sr}, 6 \mathrm{Bi})$ & $-459(5)$ & $4.4(2)$ & $0.6(2)$ & $40(2)$ & 24 & & & \\
\hline & $\mathrm{V}_{2} \mathrm{O}_{7}$ & $-500(10)$ & $4.6(2)$ & $0.6(2)$ & $66(8)$ & 6 & & & \\
\hline & $\begin{array}{l}\text { DFT }(2 \times 2 \times 1) \\
\text { supercell }\end{array}$ & $\begin{array}{l}\delta_{\text {ISO }}{ }^{\text {av }} \\
(\mathrm{ppm})\end{array}$ & $\begin{array}{l}\left|C_{Q}\right|^{\text {av }} \\
(\mathrm{MHz})\end{array}$ & $\eta_{Q^{a v}}$ & $\begin{array}{l}\sigma\left(\delta_{\mathrm{ISO}}\right) \\
(\mathrm{ppm})\end{array}$ & $\begin{array}{l}\sigma\left(\left|\boldsymbol{C}_{\mathbf{Q}}\right|\right) \\
(\mathbf{M H z})\end{array}$ & & & \\
\hline \multirow[t]{4}{*}{ c $\mathrm{Sr}_{0.125} \mathrm{Bi}_{0.875} \mathrm{VO}_{3.9375}$} & $\mathrm{VO}_{4}(\mathrm{OSr}, 8 \mathrm{Bi})$ & -446.8 & 5.40 & 0.26 & 13.6 & 0.47 & & & \\
\hline & $\mathrm{VO}_{4}(1 \mathrm{Sr}, 7 \mathrm{Bi})$ & -463.5 & 5.21 & 0.26 & 17.7 & 0.82 & & & \\
\hline & $\mathrm{VO}_{4}(2 \mathrm{Sr}, 6 \mathrm{Bi})$ & -493.4 & 4.60 & 0.26 & 9.2 & 0.99 & & & \\
\hline & $\mathrm{V}_{2} \mathrm{O}_{7}(2 \mathrm{Sr}, 5-6 \mathrm{Bi})$ & -558.1 & 8.39 & 0.62 & 11 & 1.19 & & & \\
\hline
\end{tabular}

environments in $\mathrm{Bi}_{1-x} \mathrm{Sr}_{x} \mathrm{VO}_{4-0.5 x}$ samples are reported in Table 1 and Supplementary Table 4.

The resonance at $\delta_{\text {ISO }}-417 \mathrm{ppm}$ was assigned to $\mathrm{BiVO}_{4}$-like local environments in Fig. 3. To identify the environments giving rise to the broader additional lines at $-439,-459$, and $\sim 500$ ppm in the ${ }^{51}$ V MAS NMR spectra, periodic DFT calculations of the NMR parameters were performed for different possible atomic arrangements. The Gauge Included Projector Augmented Wave $(\text { GIPAW) })^{32}$ and Projector Augmented Wave (PAW ${ }^{33}$ methods, which can predict the chemical shielding and electric field gradient (EFG) tensors in a variety of solids with a high accuracy $^{34,35}$, were employed. To create a benchmark of possible ${ }^{51} \mathrm{~V}$ local environments in $\mathrm{Bi}_{1-x} \mathrm{Sr}_{x} \mathrm{VO}_{4-0.5 x}$ compositions, several structural models accommodating oxygen vacancies and Sr cations were considered. These models were built from a $2 \times$ $2 \times 1$ supercell of the $\mathrm{BiVO}_{4}$ unit cell in which two $\mathrm{Bi}$ atoms are replaced by two $\mathrm{Sr}$ atoms and an oxygen atom of a $\mathrm{VO}_{4}$ group is removed, resulting in the formation of a $\mathrm{V}_{2} \mathrm{O}_{7}$ unit in the vicinity of Sr. A total of eight inequivalent supercell containing 95 atoms matching the $\mathrm{Sr}_{0.125} \mathrm{Bi}_{0.875} \mathrm{VO}_{3.9375}$ composition (Supplementary Fig. 13) were investigated. The DFT optimization of all atomic positions was performed with $P 1$ symmetry through constraining the cell parameters to the values presented Fig. $2 \mathrm{c}$. The optimized $2 \times 2 \times 1$ cells are shown in Supplementary Fig. 13 . DFT geometry optimization leads to average $\mathrm{Sr}-\mathrm{O}$ and $\mathrm{Bi}-\mathrm{O}$ bond lengths of $\sim 2.55$ and $2.45 \AA$ respectively, and to $\mathrm{O}-\mathrm{V}$ bridging-bond lengths of $\sim 1.82 \AA$, very close to the experimental values reported for $\mathrm{BiVO}_{4}$ and $\mathrm{Sr}_{2} \mathrm{VO}_{7}$. In the optimized models, which show very similar total energies, the $\mathrm{V}_{2} \mathrm{O}_{7}$ units are found to adopt either an almost linear or bent conformation depending on the location of Sr atoms.

The ${ }^{51} \mathrm{~V}$ isotropic chemical shifts and quadrupolar coupling constants of all V sites in the $2 \times 2 \times 1$ supercell models from the GIPAW and PAW computations are illustrated in Fig. 4. These results show that four ranges of ${ }^{51} \mathrm{~V} \delta_{\text {IsO }}$ values can be identified in the $2 \times 2 \times 1 \mathrm{Sr}_{0.125} \mathrm{~B}_{0.875} \mathrm{O}_{3.9375}$ models, in good agreement with the experimental spectra. The former with an average ${ }^{51} \mathrm{~V}$ $\delta_{\text {ISO }}$ of $-446.8 \mathrm{ppm}$, corresponding to $\mathrm{BiVO}_{4}$-like environment (i.e., isolated $\mathrm{VO}_{4}$ tetrahedron surrounded by eight $\mathrm{Bi}$ atoms), is close to the value calculated for parent $\mathrm{BiVO}_{4}(-439 \mathrm{ppm})$. Two calculated $\delta_{\text {ISO }}$ values centered at -463.5 and $-493.4 \mathrm{ppm}$ correspond to isolated $\mathrm{VO}_{4}$ groups with one and two Sr atoms in their second coordination spheres, respectively. Finally, the fourth calculated ${ }^{51} \mathrm{~V} \delta_{\text {ISO }}$ with an average value at $-558.1 \mathrm{ppm}$ corresponds to the inequivalent $\mathrm{V}$ sites in $\mathrm{V}_{2} \mathrm{O}_{7}$ groups. Considering the calculated and experimental $\delta_{\text {ISO }}$ values for $\mathrm{BiVO}_{4}$ (of -439 and $419 \mathrm{ppm}$, respectively) as internal references, the computational results nicely mimic the experimental trends and the four contributions at $-417,-439,-459$, and $-500 \mathrm{ppm}$ in the experimental MAS NMR spectra can be confidently assigned to isolated $\mathrm{VO}_{4}$ groups with 0,1 , and $2 \mathrm{Sr}$ neighbors and to $\mathrm{V}_{2} \mathrm{O}_{7}$ units, respectively. Calculated average $\left|C_{\mathrm{Q}}\right|$ values are also in good agreement with experimental values for isolated $\mathrm{VO}_{4}$ groups, while overestimated values are obtained for the $\mathrm{V}_{2} \mathrm{O}_{7}$ units, possibly due to the limited number of $\mathrm{V}_{2} \mathrm{O}_{7}$ local conformations considered in the structural models $\left(1 \mathrm{~V}_{2} \mathrm{O}_{7}\right.$ dimer for a $2 \times 2 \times 1$ supercell of $\mathrm{Sr}_{0.125} \mathrm{Bi}_{0.875} \mathrm{VO}_{3.9375}$ ). Following the above line assignment, the amount of $\mathrm{V}$ atoms involved in $\mathrm{V}_{2} \mathrm{O}_{7}$ units determined from MAS spectra are 4, 6, 16, and 20\% for $x=0.05,0.1,0.15$, and 0.2 , respectively, very close to the values expected from sample compositions $(5,10,15$, and $20 \%)$.

Clearly, both experimental and computational NMR results indicate that generation of oxygen vacancies in $\mathrm{Bi}_{1-x} \mathrm{Sr}_{x} \mathrm{O}_{4-0.5 x}$ Scheelite structure occurs via formation of bridging $\mathrm{V}-\mathrm{O}-\mathrm{V}$ bonds to avoid the formation of unstable three-fold coordinated $\mathrm{V}$ centers.

Ionic conductivity. Figure 5 a shows the complex impedance plot of parent $\mathrm{BiVO}_{4}$ at $300^{\circ} \mathrm{C}$, which comprises bulk, grain boundary, and electrode responses. The large semicircular arc in the high-frequency region displays capacitances of $\sim 8-10 \mathrm{pF} \mathrm{cm}^{-1}$ (inset of Fig. 5a), ascribed to the bulk response ${ }^{36}$, which may be simply modeled by a parallel resistor $\left(R_{\mathrm{b}}\right)$ and capacitor $\left(C_{\mathrm{b}}\right)$. The intercept of the large semicircular arc at low frequency was extracted as the bulk resistivity $R_{\mathrm{b}}$ and the associated $C_{\mathrm{b}}$ calculated by using the equation $\omega \mathrm{RC}=1\left(\omega=2 \pi f_{\max }\right.$, where $f_{\max }$ is the frequency at maximum imaginary impedance $Z_{\max }^{\prime \prime}$; $\omega$ is also equal to the inverse of the relaxation time $\tau$ ) is $10 \mathrm{pF} \mathrm{cm}^{-1}$. This value is close to that calculated using $M_{\max }^{\prime \prime}=\varepsilon_{0} / 2 C^{37}$, where $M_{\max }^{\prime \prime}$ is the maximum imaginary modulus for this semicircular arc. This indicates that the imaginary impedance and modulus 


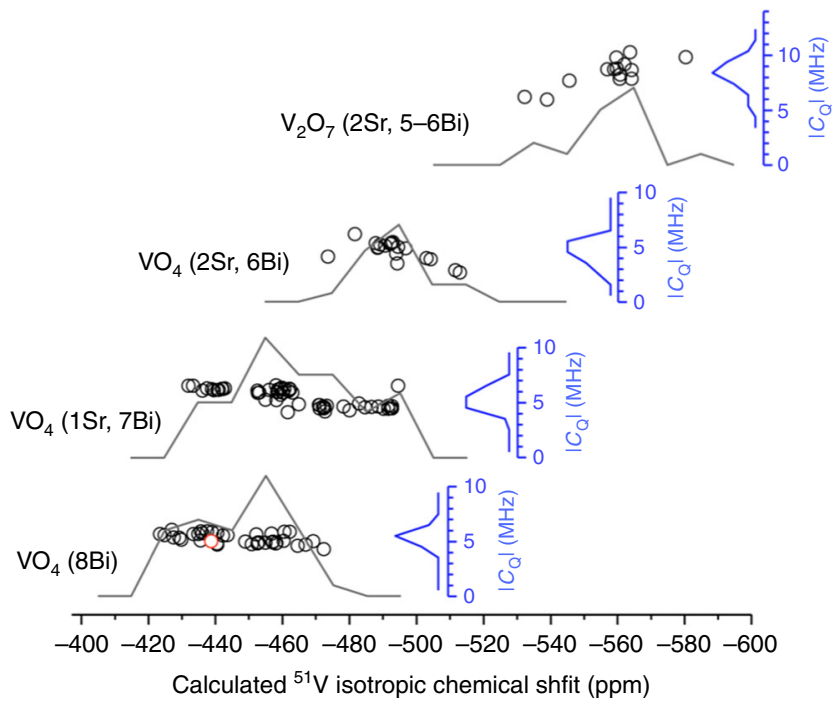

Fig. 4 Calculated ${ }^{51} \mathrm{~V}$ isotropic chemical shift. Calculated ${ }^{51} \mathrm{~V}$ isotropic chemical shift $\left(\delta_{\mathrm{ISO}}\right)$ and quadrupolar coupling constants $\left(\left|\mathrm{C}_{\mathrm{Q}}\right|\right)$ for isolated $\mathrm{VO}_{4}$ tetrahedra with different number of $\mathrm{Sr} / \mathrm{Bi}$ atom neighbors in their second coordination spheres and $\mathrm{V}_{2} \mathrm{O}_{7}$ dimers in $\mathrm{Sr}_{0.125} \mathrm{Bi}_{0.875} \mathrm{VO}_{3.9375}$. Black and blue lines correspond to histograms of calculated $\delta_{\mathrm{ISO}}$ and $\left(\left|C_{\mathrm{Q}}\right|\right)$, respectively peaks (Supplementary Fig. 14) in the high-frequency region are associated with the same RC elements, that is, that the large semicircular arc can be ascribed to a single bulk respons ${ }^{37}$. The grain boundary response overlaps significantly with the electrode response, giving an essentially flattened/depressed arc in the low-frequency region. The deconvolution of the impedance plot for $\mathrm{BiVO}_{4}$ at $300^{\circ} \mathrm{C}$, performed through the equivalent circuit fitting with bulk, grain boundary, and electrode components (see Supplementary Note 2 for details), is shown in Fig. 5a. The large capacitance of $\sim 10^{-8}-10^{-7} \mathrm{~F} \mathrm{~cm}^{-1}$ in the $10-0.1 \mathrm{~Hz}$ low-frequency region is indicative of ionic conduction in parent $\mathrm{BiVO}_{4}{ }^{36}$. With the increase of temperature, the bulk response arc gradually disappears, which results in the mixed grain boundary and electrode-response arcs observed at $700{ }^{\circ} \mathrm{C}$ (Supplementary Fig. 15a).

The impedance data for the strontium-substituted compositions contain significant Warburg-type electrode response in addition to the bulk and grain boundary responses (Fig. 5b), suggesting that ionic conduction is enhanced by the $\mathrm{Sr}$ substitution. Figure $5 \mathrm{~b}$ shows the complex impedance plot and its deconvolution for a $\mathrm{Bi}_{0.95} \mathrm{Sr}_{0.05} \mathrm{VO}_{3.975}$ pellet at $300^{\circ} \mathrm{C}$. With the increase of temperature, both bulk and grain boundary responses gradually disappear and the electrode response collapsed down to semicircular arc at high temperature in air (Supplementary Fig. 15b and Supplementary Fig. 16a). Under low partial oxygen pressure $\left(p \mathrm{O}_{2}\right) \mathrm{N}_{2}$ environment, the electrode-
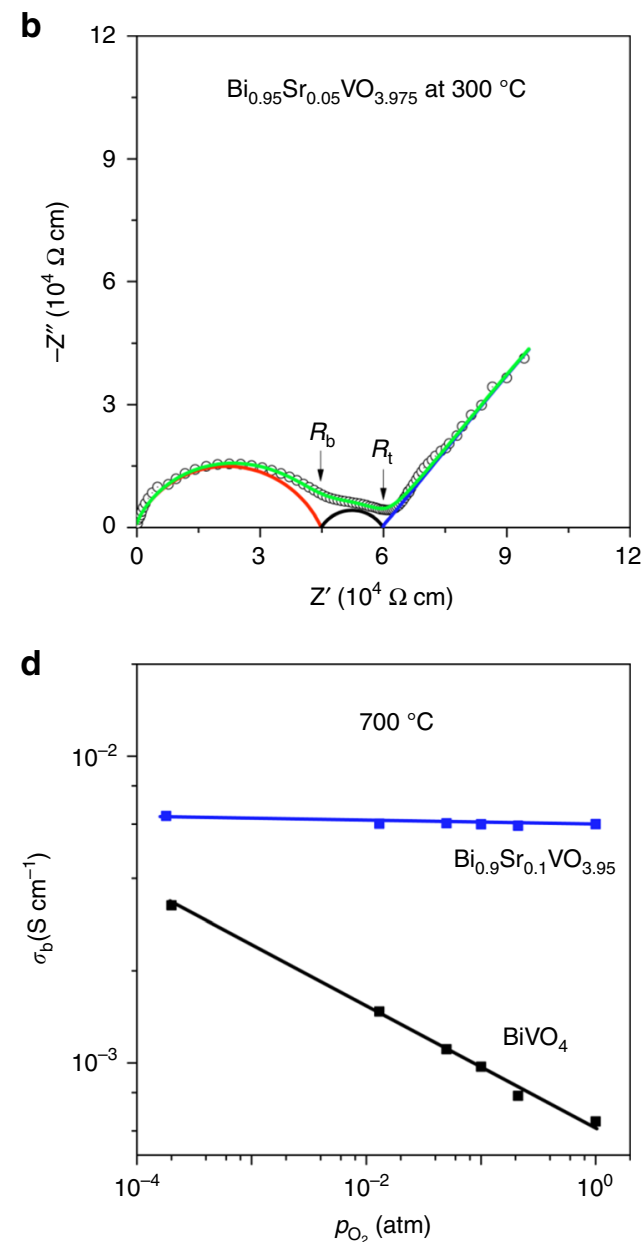

Fig. 5 Ionic conductivity. Typical complex impedance plots at $300{ }^{\circ} \mathrm{C}$ of $\mathbf{a} \mathrm{BiVO}_{4}$ and $\mathbf{b} \mathrm{Bi}_{0.95} \mathrm{Sr}_{0.05} \mathrm{VO}_{3.975}$ and their fitted curves (green), as well as the deconvolution of bulk (red), grain boundary (black), and electrode (blue)-response arcs. $R_{\mathrm{b}}$ and $R_{\mathrm{t}}$ denote bulk and total resistivities, respectively. The inset in a shows the capacitance as a function of frequency. $\mathbf{c}$ Arrhenius plots of the conductivities for $\mathrm{Bi}_{1-x} \mathrm{Sr}_{x} \mathrm{VO}_{4-0.5 x}(x=0-0.2)$. The inset shows the bulk conductivity at $500{ }^{\circ} \mathrm{C}$ as a function of $x$. $\mathbf{d}$ The $\mathrm{pO}_{2}$ dependency of the conductivity of $\mathrm{BiVO}_{4}$ and $\mathrm{Bi}_{0.9} \mathrm{Sr}_{0.1} \mathrm{VO}_{3.95}$ at $700{ }^{\circ} \mathrm{C}$ 
response arc reverted back to a Warburg-type spike characteristic of oxide ion conduction (Supplementary Fig. 16a), in contrast with the parent $\mathrm{BiVO}_{4}$ pellet for which the electrode-response arc remained as a semicircular arc shape (Supplementary Fig. 16b). Such a behavior, for the Sr-substituted compositions of the electrode-response arc versus $\mathrm{pO}_{2}$, is consistent with the $p \mathrm{O}_{2}$ controlled kinetics of the oxygen ion diffusion and charge transfer reaction of $\mathrm{O}_{2}+2 \mathrm{e} \leftrightarrow 2 \mathrm{O}^{2-}$ along the sample-electrode-gas interface, similar to common observations in oxide ion conductors $^{38-40}$. Thus, the oxide ion conductivity is enhanced by the $\mathrm{Sr}$ substitution for $\mathrm{Bi}$ in $\mathrm{BiVO}_{4}$.

The Arrhenius plots of bulk conductivities (Fig. 5c) for $\mathrm{Bi}_{1-x} \mathrm{Sr}_{x} \mathrm{VO}_{4-0.5 x}$ show a conductivity increase by at least one order of magnitude in the Sr-substituted compositions compared with the parent material below $600{ }^{\circ} \mathrm{C}$. The conductivity of the parent $\mathrm{BiVO}_{4}$ varies within $10^{-6}-10^{-4} \mathrm{~S} \mathrm{~cm}^{-1}$ between 300 and $600^{\circ} \mathrm{C}$. The $x=0.05$ composition displays the highest conductivity $\left(10^{-5}-10^{-3} \mathrm{~S} \mathrm{~cm}^{-1}\right)$ among the substituted compositions in the same temperature region and an activation energy $\left(E_{\mathrm{a}}\right)$ of 0.74 (2) $\mathrm{eV}$, close to $0.77(1) \mathrm{eV}$ for $\mathrm{BiVO}_{4}$. The parent $\mathrm{BiVO}_{4}$ displays significant increase of $E_{\mathrm{a}}$ to $1.37(5) \mathrm{eV}$ above $600^{\circ} \mathrm{C}$, which led to a conductivity at $700{ }^{\circ} \mathrm{C}$ for $\mathrm{BiVO}_{4}$ almost matching those of the Sr-substituted compositions (Fig. 5c). In order to confirm the nature of the charge carriers, oxygen transport numbers $\left(t_{\mathrm{O}^{2-}}\right)$ in $\mathrm{Bi}_{1-x} \mathrm{Sr}_{x} \mathrm{VO}_{4-0.5 x}(x=0,1)$ were determined via electromotive force (EMF) measurements of oxygen concentration cells within $500-700^{\circ} \mathrm{C}$. Owing to the large-size samples required for the EMF measurements compared to the size limitation of the samples synthesized by the ADL method, the $x=0$ and 0.1 pellets from the CSS route were used in the oxygen concentration cells, although the $x=0.1$ sample is composed of a mixture of the monoclinic and tetragonal polymorphs. As indicated by the VTXRD data (Supplementary Fig. 17), this two-polymorph system eventually transformed to single tetragonal polymorph above 150 ${ }^{\circ} \mathrm{C}$, similarly to the single-monoclinic-phase sample $x=$ 0.1 synthesized from the ADL method (Supplementary Fig. 7a, c). Therefore, the oxygen transport numbers measured at high temperatures on the $x=0.1$ pellet from the CSS route are indeed referring to single tetragonal phase, similarly to those for the pristine $\mathrm{BiVO}_{4}$ material synthesized from the CSS route, as well as the conductivity properties of the single-phase $\mathrm{Bi}_{1-x} \mathrm{Sr}_{x} \mathrm{VO}_{4-0.5 x}$ samples obtained from the $\mathrm{ADL}$ method that were recorded above the phase transition temperatures.

The parent $\mathrm{BiVO}_{4}$ has a $t_{\mathrm{O}^{2-}}$ value $\sim 0.27$ at $500{ }^{\circ} \mathrm{C}$, which decreases down by $\sim 50 \%$ to 0.12 at $700^{\circ} \mathrm{C}$. This confirms mixed electronic-ionic conduction in $\mathrm{BiVO}_{4}$ and suggests that the electronic conduction becomes more dominative over the oxide ionic conduction at elevated temperature, which could explain the increase of $E_{\mathrm{a}}$ for the parent $\mathrm{BiVO}_{4}$ at $>600^{\circ} \mathrm{C}$ (Fig. 5c). The $\mathrm{pO}_{2}$ dependency of the conductivity at $700{ }^{\circ} \mathrm{C}$ (Fig. 5d) suggests ntype electronic conduction in the parent $\mathrm{BiVO}_{4}$. The existence of a low level of oxide ion conduction in the parent $\mathrm{BiVO}_{4}$ could be ascribed to the possible uncontrollable Bi deficiency owing to the volatilization of $\mathrm{Bi}_{2} \mathrm{O}_{3}$ during the material preparation, which could result in the presence of oxygen vacancies. Bi nonstoichiometry effect on the oxide ion conduction has been demonstrated in $\mathrm{Na}_{0.5} \mathrm{Bi}_{0.5} \mathrm{TiO}_{3}$-based oxide ion conductors ${ }^{38,39,41}$.

$\mathrm{Bi}_{0.9} \mathrm{Sr}_{0.1} \mathrm{VO}_{3.95}$ has $t_{\mathrm{O}^{2-}}$ values $\sim 0.71-0.88$ within $500-700^{\circ} \mathrm{C}$, which together with the enhanced conductivities (Fig. $5 \mathrm{c}$ ) and the electrode-response-arc behavior of $\mathrm{pO}_{2}$ (Supplementary Fig. 16a) confirm that the oxide ionic conduction in $\mathrm{BiVO}_{4}$ is apparently enhanced upon the $\mathrm{Sr}^{2+}$ substitution for $\mathrm{Bi}^{3+}$. No significant changes of $t_{\mathrm{O}^{2-}}$ were observed as a function of the temperature and the conductivity of $\mathrm{Bi}_{0.9} \mathrm{Sr}_{0.1} \mathrm{VO}_{3.95}$ at $700{ }^{\circ} \mathrm{C}$ is essentially $\mathrm{pO}_{2}$-independent (Fig. 5d), indicating that in the Sr-substituted compositions the oxide ionic conduction predominates over the electronic conduction for the measured temperature region in high $\mathrm{pO}_{2}$ atmospheres.

Oxygen vacancy migration. In order to elucidate how the oxygen vacancies migrate in the Scheelite structure, atomistic static lattice and MD simulations based on the interatomic potential method were performed, as previously successfully applied in other structure types based on tetrahedral units, for example, apatitebased $^{9}$, melilite-based ${ }^{12}$, and $\mathrm{LaBaGaO}_{4}$-based ${ }^{3}$ oxide ion conductors. The potential parameters listed in Supplementary Table 5 well reproduce the Scheelite $\mathrm{BiVO}_{4}$ structure. The differences between calculated and experimental cell parameters and bond lengths (Supplementary Table 6) are $< \pm 0.06$ and $\pm 0.2 \AA$, respectively. It is interesting to note that the calculated $\mathrm{BiVO}_{4}$ structure appears as a tetragonal structure (Supplementary Table 6). Given that the conductivity data described above correspond to the high-temperature tetragonal phase of $\mathrm{Bi}_{1-x} \mathrm{Sr}_{x}$ $\mathrm{VO}_{4-0.5 x}$, the calculated $\mathrm{BiVO}_{4}$ structure led to an excellent structural model for the MD simulation of oxygen vacancy migration in the Sr-substituted $\mathrm{BiVO}_{4}$, although the weak distortion of $\mathrm{VO}_{4}$ tetrahedra in the room temperature monoclinic Scheelite structure is not reproduced. The calculated solution energy of $\mathrm{Sr}^{2+}$ on $\mathrm{Bi}^{3+}$ site via the defect reaction $2 \mathrm{SrO}+$ $2 \mathrm{Bi}_{\mathrm{Bi}}^{\times}+\mathrm{O}_{\mathrm{O}}^{\times} \rightarrow 2 \mathrm{Sr}_{\mathrm{Bi}}^{\prime}+\mathrm{V}_{\mathrm{O}}^{*}+\mathrm{Bi}_{2} \mathrm{O}_{3}$ is $\sim 1.67 \mathrm{eV}$, which is consistent with the solubility of $\mathrm{Sr}^{2+}$ in $\mathrm{Bi}^{3+}$ site in the $\mathrm{BiVO}_{4}$ Scheelite. MD simulations indicate that in the Sr-substituted $\mathrm{BiVO}_{4}$ Scheelite materials, the long-range migration of oxygen vacancies (Fig. 6a and Supplementary video file) takes place via the continuous breaking and reforming of $\mathrm{V}_{2} \mathrm{O}_{7}$ dimer. Such an oxygen vacancy migration is allowed by a cooperative mechanism involving the synergic rotation and deformation of neighboring $\mathrm{VO}_{4}$ tetrahedra that transfer oxide anions between $\mathrm{V}_{2} \mathrm{O}_{7}$ and $\mathrm{VO}_{4}$ units, thus allowing the $\mathrm{V}_{2} \mathrm{O}_{7}$-dimer breaking and reforming process, akin to $\mathrm{La}_{1-x} \mathrm{Ba}_{1+x} \mathrm{GaO}_{4-0.5 x}$ case ${ }^{3}$. The scatter plot of oxygen ions (Fig. 6b) shows long-range diffusion paths in Srsubstituted $\mathrm{BiVO}_{4}$ arising from $\mathrm{V}_{2} \mathrm{O}_{7}$-dimer breaking and reforming. The streaming and overlapping of colors of oxygen ions in the scatter plot and the mean square displacement (MSD) plots (Fig. 6c) suggest that both distinctly crystallographic oxygen sites $\mathrm{O} 1$ and $\mathrm{O} 2$ are involved in the oxide ion migration. This observation is consistent with the cooperative rotation and deformation of $\mathrm{VO}_{4}$ tetrahedra required for exchanging the oxide anions, and in agreement with the results from Rietveld refinements, which indicate the presence of oxygen vacancies in both oxygen sites. In contrast, heavier $\mathrm{Bi}^{3+}, \mathrm{Sr}^{2+}$, and $\mathrm{V}^{5+}$ cations vibrate around their lattice positions without long-range migration (Fig. 6c). The MSD values of oxygen atoms were used to calculate the oxygen diffusion coefficient, which is estimated as $\sim 2 \times 10^{-7}-7 \times 10^{-8} \mathrm{~cm}^{2} \mathrm{~s}^{-1}$ within the $1200-1600^{\circ} \mathrm{C}$ temperature range, although no experimental values are available for comparison. The activation energy of $\sim 0.57 \mathrm{eV}$ derived from the Arrhenius plot of the calculated oxygen diffusion coefficients (Supplementary Fig. 18) is lower than experimental values from the conductivity measurements $(\sim 0.74 \mathrm{eV})$.

The ability to accommodate and transport the oxygen vacancies demonstrated in $\mathrm{Bi}_{1-x} \mathrm{Sr}_{x} \mathrm{VO}_{4-0.5 x}$ make the $\mathrm{BiVO}_{4}$ Scheelite structure unique when compared with other reported Scheelite compositions which can hardly accommodate mobile oxygen vacancies. The fluorite-like $\mathrm{Bi}-\mathrm{O}$ sublattice, which is known as a highly polarizable bonding network ${ }^{16,38,41}$, could offer flexible environments to adapt for rotation and deformation of $\mathrm{VO}_{4}$ tetrahedra, which is important for the stabilization and migration of oxygen vacancies in a tetrahedra-based structure. Therefore, the Bi-O lattice provides pathways with low diffusion barriers, which are highly beneficial for the migration of oxygen 

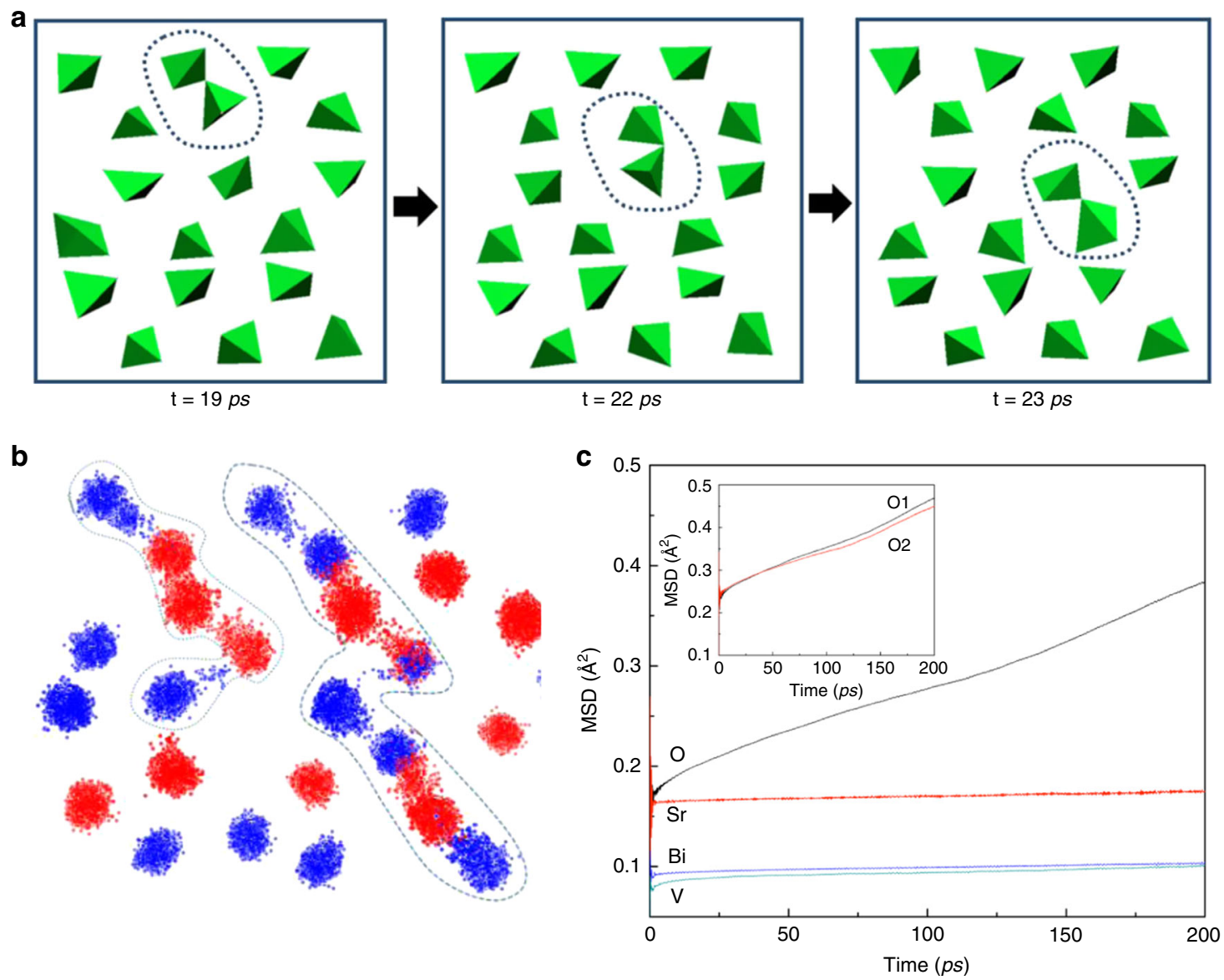

Fig. 6 Oxygen vacancy migration in $\mathrm{Sr}_{0.0625} \mathrm{Bi}_{0.9375} \mathrm{VO}_{3.96875}$. a Snapshots from MD simulation at $1400{ }^{\circ} \mathrm{C}$ showing long-range oxygen vacancy migration involving $\mathrm{V}_{2} \mathrm{O}_{7}$-dimer breaking and reforming. $\mathbf{b}$ Scatter plot of oxide ion positions roughly corresponding to the dimension in $\mathbf{a}$ from $\mathrm{MD}$ simulation. The $\mathrm{V}_{2} \mathrm{O}_{7}$-dimer breaking and reforming results in long-range diffusion paths (marked by dashed lines). Blue and red dots denote oxide ions originally at $\mathrm{O} 1$ and $\mathrm{O} 2$ sites, respectively. The $\mathrm{Bi}, \mathrm{Sr}, \mathrm{V}$, and some $\mathrm{O}$ ions are omitted for clarity. c Calculated MSD values of $\mathrm{Sr}, \mathrm{Bi}, \mathrm{V}$, and $\mathrm{O}$ atoms as function of time from the $\mathrm{MD}$ simulation at $1400^{\circ} \mathrm{C}$. The inset shows the MSD values for $\mathrm{O}$ atoms originally at sites $\mathrm{O} 1$ and $\mathrm{O} 2$, which are close to each other indicating that both oxygen sites participate equally in the oxide ion migration

ions. The creation of oxygen vacancies through Sr substitution for $\mathrm{Bi}$ could be offset by decreasing the concentration of $\mathrm{Bi}-\mathrm{O}$ bonds owing to the decrease of the metal-oxygen polarizable bonds, which could hinder further improvement on the ionic conductivity when more $\mathrm{Bi}^{3+}$ is replaced with $\mathrm{Sr}^{2+}$ in $\mathrm{BiVO}_{4}$ beyond the $x=0.05$ composition. Alternatively, the lower conductivity when $x>0.05$ compositions could be linked to the structural distortion or to the interaction between defects.

The fact that an optimal ionic conductivity can be observed for an intermediate substitution content, or oxide ion defect concentration, within a solid solution has been widely observed in oxide ion conductors ${ }^{15,42-44}$. Under high substitution concentration, interactions between the defects can act as traps for the migrating oxide ions, thereby reducing the oxide ion mobility and therefore lowering the conductivity when the substitution concentration exceeds the optimal value ${ }^{42,43}$. In the case of Sr-substituted $\mathrm{BiVO}_{4}$, the calculated association energies for $\mathrm{Sr}_{\mathrm{Bi}}^{\prime}+\mathrm{V}_{\mathrm{O}}^{*}$ and $2 \mathrm{Sr}_{\mathrm{Bi}}^{\prime}+\mathrm{V}_{\mathrm{O}}^{\prime}$ defect complexes are, respectively, 0.41 and $0.57 \mathrm{eV}$, confirming that when the Sr-substitution concentration increases, more trapping effect takes place on the vacancy migration from the defect interaction, although these energies imply that the trapping of oxygen vacancies is not significant in Sr-substituted $\mathrm{BiVO}_{4}$. The vacancy migration in $\mathrm{Bi}_{1-x} \mathrm{Sr}_{x} \mathrm{VO}_{4-0.5 x}$ requires cooperation between $\mathrm{V}_{2} \mathrm{O}_{7}$ dimer and a neighboring $\mathrm{VO}_{4}$. Therefore, the increase of oxygen vacancies will reduce the number of $\mathrm{VO}_{4}$ tetrahedral units around the $\mathrm{V}_{2} \mathrm{O}_{7}$ dimer. Ultimately, the accumulation of $\mathrm{V}_{2} \mathrm{O}_{7}$ defect units will block the vacancy migration. It is worth noting that increasing the $\mathrm{Sr} / \mathrm{Bi}$ ratio and concentration of $\mathrm{V}_{2} \mathrm{O}_{7}$ in $\mathrm{BiSr}_{2} \mathrm{~V}_{3} \mathrm{O}_{11}$ present as a secondary phase ${ }^{26}$ for $x>0.3$ (Fig. 2a), which contains ordered $\mathrm{V}_{2} \mathrm{O}_{7}$ and $\mathrm{VO}_{4}$ units in a 1:1 ratio, results in a significant dampening of the ionic conductivity (Supplementary Fig. 19). This fact further emphasizes the importance of a $\mathrm{Bi}-\mathrm{O}$ lattice and optimal oxygen vacancy content for oxide ion conduction in Sr-substituted $\mathrm{BiVO}_{4}$ Scheelite. Apart from the defect interaction and composition change, the possible existence of this insulating impurity below detection limits could also contribute to the conductivity degradation at the highly Sr-substituted compositions but such an effect is expected to be limited.

Although our work dedicates to the oxygen vacancy defect chemistry and vacancy-mediated oxide ion migration in the $\mathrm{BiVO}_{4}$ Scheelite, the fine details and understanding of the defect chemistry and structure in this work could also be useful for understanding other physical properties related to the acceptor-dopant character of $\mathrm{BiVO}_{4}$ Scheelite, for example, its well-known visible-light photocatalytic activity for the degradation of organic pollutants and water oxidation ${ }^{21,22}$. 


\section{Discussion}

$\mathrm{Sr}^{2+}$ substitution for $\mathrm{Bi}^{3+}$ in $\mathrm{BiVO}_{4}$ leads to the generation and migration of oxygen vacancies in the isolated tetrahedral anion Scheelite structure. The solid solution limit in $\mathrm{Bi}_{1-x} \mathrm{Sr}_{x} \mathrm{VO}_{4-0.5 x}$ can be extended significantly from $x=0.1$ using solid-state reaction synthesis to $x=0.3$ via direct crystallization from the melt, using ADL coupled to laser heating system as an original elaboration method. Rietveld analysis performed on powder diffraction data reveals positional disorder and the presence of oxygen vacancies in $\mathrm{Bi}_{1-x} \mathrm{Sr}_{x} \mathrm{VO}_{4-0.5 x}$. Solid-state ${ }^{51} \mathrm{~V}$ NMR spectroscopy coupled to DFT calculations allowed a precise assignment of ${ }^{51} \mathrm{~V}$ chemical shifts to the local structures, which demonstrate that the oxygen vacancies are accommodated via the formation of corner-sharing $\mathrm{V}_{2} \mathrm{O}_{7}$ tetrahedral dimers. The $\mathrm{Sr}^{2+}$ substitution reduces the monoclinic-to-tetragonal phase transition temperature of $\mathrm{BiVO}_{4}$ and significantly enhances the oxide ion conductivity by $\sim 1-2$ orders of magnitude. MD simulations indicates that oxygen vacancies migrate via a cooperative mechanism allowed by the synergic rotation and deformation of neighboring $\mathrm{VO}_{4}$ tetrahedra that assist the continuous breaking and reforming of $\mathrm{V}_{2} \mathrm{O}_{7}$ dimers. This oxygen vacancy conducting $\mathrm{Bi}_{1-x} \mathrm{Sr}_{x} \mathrm{VO}_{4-0.5 x}$ Scheelite material reported here, along with the known interstitial oxide ion conducting features of Scheelites, demonstrate that the Scheelite structure is able to incorporate oxygen vacancy or interstitial defects to facilitate high oxide ion migration. This suggests that parallel vacancy and interstitial doping strategies to the same tetrahedra-based structure type can be employed for discovery of new oxide ion conductors in the future.

\section{Methods}

Synthesis. The synthesis of $\mathrm{BiVO}_{4}$ and $\mathrm{Sr}$-substituted $\mathrm{Bi}_{1-x} \mathrm{Sr}_{x} \mathrm{VO}_{4-0.5 x}$ compositions was carried out by the CSS method and $\mathrm{ADL}^{45}$ coupled to laser heating method, which allowed extending the solid solution range in $\mathrm{Bi}_{1-x} \mathrm{Sr}_{x} \mathrm{VO}_{4-0.5 x}$ beyond the limit reached in CSS route via a two-step method: first melting (enabling strong homogenization) and then crystallizing the melt upon rapid cooling (by switching off the lasers) ${ }^{46}$.

For the CSS synthesis, $\mathrm{Bi}_{2} \mathrm{O}_{3}(99.9 \%), \mathrm{NH}_{4} \mathrm{VO}_{3}(99 \%)$, and $\mathrm{SrCO}_{3}(99 \%)$ starting materials were weighed according to the nominal $\mathrm{Bi}_{1-x} \mathrm{Sr}_{x} \mathrm{VO}_{4-0.5 x}(x=$ $0-0.2$ ) compositions and mixed in ethanol in an agate mortar. The dried powders were pressed into pellets ( $12 \mathrm{~mm}$ diameter and $\sim 2 \mathrm{~mm}$ thick) under a uniaxial pressure of $330 \mathrm{MPa}$ and calcined at $600{ }^{\circ} \mathrm{C}$ for $5 \mathrm{~h}$ in air with heating and cooling rates of $5{ }^{\circ} \mathrm{C} \mathrm{min}^{-1}$. The calcined pellets after the first step were ground and pressed once more for a final sintering step at $700{ }^{\circ} \mathrm{C}$ for $5 \mathrm{~h}$.

Regarding the ADL synthesis, stoichiometric amounts of the same starting materials were weighed and homogenized in an agate mortar using ethanol. The powder mixtures were then dried and pressed into pellets. Pieces of the powder pellets were then placed onto a metallic nozzle and were levitated under an oxygen flow. Two $\mathrm{CO}_{2}$ lasers were used to homogeneously melt the samples from top and bottom (see Supplementary Fig. 4). The melt was then left to homogenize for $30 \mathrm{~s}$. Polycrystalline bead materials ( $3 \mathrm{~mm}$ of diameter) were then obtained by crystallization from the melt by decreasing the power of the two laser beams ${ }^{45,47}$. The compositional homogeneity of the samples were analyzed by SEM and EDS using an FEI ESEM XL 40 apparatus.

Powder diffraction. The identification of the crystalline phases was performed by powder XRD using a Panalytical X'Pert diffractometer equipped with $\mathrm{Cu} \mathrm{Ka}$ radiation source. VT-XRD data were collected over the $10-80^{\circ} 2 \theta$ range at every 50 ${ }^{\circ} \mathrm{C}$ from room temperature up to $800^{\circ} \mathrm{C}$ during both heating and cooling steps, allowing $3 \mathrm{~min}$ for temperature equilibration before collecting the data sets for 8 min. Laboratory XRD data were analyzed using the Topas-Academic software ${ }^{48}$

High-intensity and high-resolution SPD data were recorded on the 11BM diffractometer at the Advanced Photon Source, Argonne National Laboratory. SPD data were collected over the $0.5-40^{\circ} 2 \theta$ range with a $0.001^{\circ}$ step size at room temperature using $\lambda=0.4593 \AA$. In order to avoid important absorption effects from the sample, which could hinder fine structural analysis, Si-glass capillaries were coated with a layer of sample powder mixed with silicone grease. The Si-glass capillaries were then introduced in Kapton capillaries which were sealed by clay. On the other hand, constant-wavelength $(\lambda=1.225 \AA)$ NPD data were collected at ambient temperature over the $10-120^{\circ} 2 \theta$ range at $2 \theta$ intervals of $0.05^{\circ}$ on the $3 \mathrm{~T} 2$ diffractometer at Laboratoire Leon Brillouin (France). The large volume of $\mathrm{Bi}_{0.9} \mathrm{Sr}_{0.1} \mathrm{VO}_{3.95}$ powdered sample for neutron diffraction was obtained by the combination of multiple beads from ADL route that were grounded and prepared in a vanadium can. Rietveld analysis of SPD and NPD data was performed using the Jana2006 package ${ }^{49}$.

Solid-state NMR. ${ }^{51} \mathrm{~V}$ solid-state NMR experiments were performed on Bruker Avance III spectrometers operating at magnetic fields of 20.0 and $9.4 \mathrm{~T}$ (corresponding ${ }^{51} \mathrm{~V}$ Larmor frequencies of 223.6 and $105.2 \mathrm{MHz}$ ) using Bruker 1.3 and $2.5 \mathrm{~mm}$ MAS probe heads. ${ }^{51} \mathrm{~V}$ quantitative MAS spectra of the $\mathrm{Bi}_{1-x} \mathrm{Sr}_{x} \mathrm{VO}_{4-0.5 x}$ samples were recorded at spinning frequencies of $60 \mathrm{kHz}(20.0 \mathrm{~T})$ and $30 \mathrm{kHz}(9.4$ $\mathrm{T})$, using short pulse lengths corresponding to a $9^{\circ}$ flip angle ${ }^{50}\left(0.25 \mu\right.$ s with $v_{\text {nut }}=$ $167 \mathrm{kHz}$ at $20.0 \mathrm{~T}$ and $0.50 \mu \mathrm{s}$ with $v_{\text {nut }}=50 \mathrm{kHz}$ at $9.4 \mathrm{~T}$ ) and a recycle delay of $1 \mathrm{~s}$. Triple-quantum magic-angle spinning $2 \mathrm{D}$ spectra were recorded at $9.4 \mathrm{~T}$ (spinning frequency of $30 \mathrm{kHz}$ ) using the Z-filter sequence ${ }^{51}$. Triple-quantum coherence excitation and reconversion were performed with a nutation frequency of $45 \mathrm{kHz}$. Eighty rotor-synchronized $t_{1}$ time increments were recorded with 672 transients each using a recycle delay of $1 \mathrm{~s} .{ }^{51} \mathrm{~V}$ chemical shifts were referenced relative to neat $\mathrm{VOCl}_{3}(0 \mathrm{ppm})$ using a $0.16 \mathrm{M} \mathrm{NaVO}_{3}$ aqueous solution as secondary standard $(-574.4 \mathrm{ppm})^{52} \cdot{ }^{51} \mathrm{~V}$ chemical shifts and quadrupolar coupling parameters of each resonance were determined from fits of the whole spinning sideband manifold observed for all seven ${ }^{51} \mathrm{~V}$ transitions in MAS spectra ${ }^{53,54}$ using the DMfit program $^{55}$

Ionic conductivity measurement. Alternating-current (AC) impedance spectroscopy measurements were performed with a Solartron 1260 frequency response analyzer over a frequency range of $10^{-1}-10^{7} \mathrm{~Hz}$ within the $100-700{ }^{\circ} \mathrm{C}$ temperature range. Gold paste was coated on the opposite faces of the pellets and heat treated at $550{ }^{\circ} \mathrm{C}$ for $40 \mathrm{~min}$ to burn out the organic components in the paste to form gold electrodes. The impedance data analysis was carried out using the ZView software ${ }^{56}$. The oxygen transport number was determined by EMF measurements on oxygen concentration cells ${ }^{57}$ of $\mathrm{O}_{2} \|$ air and $\mathrm{N}_{2} \|$ air at $500-700^{\circ} \mathrm{C}$. The pellets were attached on the alumina tube using a glass sealant heat treated at $750{ }^{\circ} \mathrm{C}$. The gas tightness was examined by using soapy water after cooling down to room temperature to ensure the absence of gas leakage prior to high temperature EMF measurements. The theoretical EMF values of the oxygen concentration cells were calculated using the Nernst equation. The partial oxygen pressure $\left(p \mathrm{O}_{2}\right)$ in the $\mathrm{N}_{2}$ gas was determined as $10^{-4}$ atm by an YSZ sensor at $800^{\circ} \mathrm{C}$. The oxygen transport numbers were calculated from the ratio of experimental and theoretical EMF values. The $\mathrm{AC}$ conductivities as a function of $\mathrm{pO}_{2}$ were measured at $700{ }^{\circ} \mathrm{C}$ over a high $p \mathrm{O}_{2}$ range of $10^{-4}-1 \mathrm{~atm}$, monitored by the $\mathrm{YSZ}$ sensor that is placed close to the sample. The $\mathrm{pO}_{2}$ was controlled using $\mathrm{O}_{2}-\mathrm{N}_{2}$ (within $1-10^{-4} \mathrm{~atm}$ ) gas mixtures, for which the HORIBA mass flow controllers (S48 32/HMT) were used. Use of lower- $\mathrm{pO}_{2}$ gas resulted in decomposition of $\mathrm{Bi}_{1-x} \mathrm{Sr}_{x} \mathrm{VO}_{4-0.5 x}$.

DFT calculation. DFT calculations of the ${ }^{51} \mathrm{~V}$ chemical magnetic shielding and EFG tensors with periodic boundary conditions were performed with the CASTEP (8.0) $\operatorname{code}^{58}$. The PAW ${ }^{33}$ and GIPAW ${ }^{32}$ methods were employed for computing the EFG and NMR chemical shielding tensors, respectively. Electron correlation effects were described using the Perdew-Burke-Ernzerhof generalized gradient approximation ${ }^{59}$ and the core-valence interactions were described by ultrasoft pseudopotentials (USPPs) ${ }^{60}$ generated using the on-the-fly generator included in the CASTEP. Further descriptions of the pseudopotentials employed are given in Supplementary Table 7. For all computations, an energy cut-off of $600 \mathrm{eV}$ was used for the plane wave basis set expansion and the Brillouin zone was sampled using a Monkhorst-Pack grid spacing of $0.04 \AA^{-1}$. Computations for the

$\mathrm{Bi}_{0.875} \mathrm{Sr}_{0.125} \mathrm{VO}_{3.9375} 2 \times 2 \times 1$ supercell models ( 95 atoms) were performed after DFT optimization of atomic positions ( $P 1$ symmetry with cell parameters fixed to Rietveld refined values with a very high accuracy) using the same USPP and computational parameters. The ${ }^{51} \mathrm{~V}$ isotropic chemical shifts $\left(\delta_{\text {ISO }}\right)$ were deduced from calculated isotropic shielding values $\left(\sigma_{\text {ISO }}\right)$ using the relationship $\delta_{\text {ISO }}=$ $-0.95(10) \sigma_{\text {ISO }}-1889(145)$, which accounts for systematic errors on calculated values using this method. The relationship was obtained from the linear regression

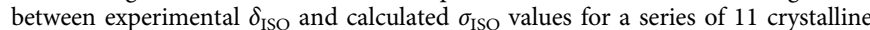
vanadate compounds of known structures (Supplementary Table 8 and Supplementary Fig. 20). For all reference compounds, DFT optimization of atomic positions (keeping symmetry constraints with cell parameters fixed to experimental values) was performed prior to GIPAW calculations. Computational parameters were the same as those described above.

Static lattice and MD simulations. The atomistic static lattice simulation based on the interatomic-potential approach ${ }^{61}$ for calculation of defect formation energy in the $\mathrm{BiVO}_{4}$ Scheelite structure was performed using the General Utility Lattice Program (GULP) ${ }^{62}$. The Buckingham potential function ${ }^{63}$ was used to describe the interactions between ions with the shell model ${ }^{63}$ to describe the electronic polarizability for the structure modeling of $\mathrm{BiVO}_{4}$. The potential parameters used for the atomistic simulation of $\mathrm{Sr}$-substituted $\mathrm{BiVO}_{4}$ are described in Supplementary Table 5. The $\mathrm{Bi}^{3+}-\mathrm{O}^{2-}, \mathrm{Sr}^{2+}-\mathrm{O}^{2-}$, and $\mathrm{V}^{5+}-\mathrm{O}^{2-}$ potential parameters were taken from previous studies ${ }^{64-66} \cdot \mathrm{Bi}^{3+}-\mathrm{Bi}^{3+}$ and $\mathrm{O}^{2-}-\mathrm{O}^{2-}$ potential parameters were obtained through the relaxed fitting procedure implemented in the GULP code based on the initial parameters from Abrahams et al. ${ }^{64}$ via refining the $A$ values only during the fitting for a better reproduction of the $\mathrm{BiVO}_{4}$ Scheelite structure. 
The extrinsic and intrinsic defect formation energies were then calculated based on appropriate combinations of vacancy, interstitial, and dopant defect energy terms. The oxygen vacancy migration mechanism in $\mathrm{Sr}$-substituted $\mathrm{BiVO}_{4}$ was investigated by interatomic-potential-based MD simulations, which were performed with the DL_POLY code ${ }^{67}$. The simulation box consisted of $8 \times 8 \times 4$ unit cells containing 6112 atoms and corresponding to a $\mathrm{Sr}_{0.0625} \mathrm{Bi}_{0.9375} \mathrm{VO}_{3.96875}$ composition. The Sr dopants and oxygen vacancies were distributed randomly within the simulation box. The systems were equilibrated first under a constant pressure of 1 atm at specific temperatures between $1200^{\circ} \mathrm{C}$ and $1600^{\circ} \mathrm{C}$ for 750,000 time steps with a time step of $0.2 \mathrm{fs}$ before carrying out the main MD simulation for $300 \mathrm{ps}$ with $1.5 \times 10^{6}$ time steps in the NVT ensemble. The Visual MD package ${ }^{68}$ was used to perform MD data analysis and the MSDs were calculated with the nMoldyn code $^{69}$. Oxygen diffusion coefficients are calculated from the slope of the MSD plots as a function of simulation time.

\section{Data availability}

All relevant data supporting the findings of this study are available from the corresponding authors upon request.

Received: 1 February 2018 Accepted: 7 October 2018

Published online: 26 October 2018

\section{References}

1. Kuang, X. et al. Interstitial oxide ion conductivity in the layered tetrahedral network melilite structure. Nat. Mater. 7, 498-504 (2008).

2. Lacorre, P., Goutenoire, F., Bohnke, O., Retoux, R. \& Laligant, Y. Designing fast oxide ion conductors based on $\mathrm{La}_{2} \mathrm{Mo}_{2} \mathrm{O}_{9}$. Nature 404, 856-858 (2000).

3. Kendrick, E., Kendrick, J., Knight, K. S., Islam, M. S. \& Slater, P. R. Cooperative mechanisms of fast-ion conduction in gallium-based oxides with tetrahedral moieties. Nat. Mater. 6, 871-875 (2007).

4. Orera, A. \& Slater, P. R. New chemical systems for solid oxide fuel cells. Chem. Mater. 22, 675-690 (2009).

5. Malavasi, L., Fisher, C. A. J. \& Islam, M. S. Oxide-ion and proton conducting electrolyte materials for clean energy applications: structural and mechanistic features. Chem. Soc. Rev. 39, 4370-4387 (2010).

6. Evans, I. R., Howard, J. A. K. \& Evans, J. S. O. The crystal structure of $\alpha-$ $\mathrm{La}_{2} \mathrm{Mo}_{2} \mathrm{O}_{9}$ and the structural origin of the oxide ion migration pathway. Chem. Mater. 17, 4074-4077 (2005).

7. Pramana, S. S. et al. Correlation of local structure and diffusion pathways in the modulated anisotropic oxide ion conductor $\mathrm{CeNbO}_{4.25}$. J. Am. Chem. Soc. 138, 1273-1279 (2016)

8. Kendrick, E., Islam, M. S. \& Slater, P. R. Developing apatites for solid oxide fuel cells: insight into structure, transport and doping properties. J. Mater. Chem. 17, 3104-3111 (2007)

9. Panchmatia, P. M. et al. Oxygen defects and novel transport mechanisms in apatite ionic conductors: combined ${ }^{17} \mathrm{O}$ NMR and modeling studies. Angew. Chem. Int. Ed. 50, 9328-9333 (2011).

10. Tate, M. L. et al. New apatite-type oxide ion conductor, $\mathrm{Bi}_{2} \mathrm{La}_{8}\left[\left(\mathrm{GeO}_{4}\right)_{6}\right] \mathrm{O}_{3}$ : structure, properties, and direct imaging of low-level interstitial oxygen atoms using aberration-corrected scanning transmission electron microscopy. Adv. Funct. Mater. 27, 1605625 (2017).

11. $\mathrm{Li}, \mathrm{M}$. R. et al. Interstitial oxide ion order and conductivity in $\mathrm{La}_{1.64} \mathrm{Ca}_{0.36} \mathrm{Ga}_{3} \mathrm{O}_{7.32}$ melilite. Angew. Chem. Int. Ed. 49, 2362-2366 (2010).

12. Tealdi, C., Mustarelli, P. \& Islam, M. S. Layered $\mathrm{LaSrGa}_{3} \mathrm{O}_{7}$-based oxide-ion conductors: cooperative transport mechanisms and flexible structures. $A d v$. Funct. Mater. 20, 3874-3880 (2010).

13. Xu, J. G., Wang, J. H., Tang, X., Kuang, X. J. \& Rosseinsky, M. J. La $\mathrm{La}_{1+x} \mathrm{Ba}_{1}$ ${ }_{-} \mathrm{Ga}_{3} \mathrm{O}_{7+0.5 x}$ oxide ion conductor: cationic size effect on the interstitial oxide ion conductivity in gallate melilites. Inorg. Chem. 56, 6897-6905 (2017).

14. Boyer, M. et al. First transparent oxide ion conducting ceramics synthesized by full crystallization from glass. J. Mater. Chem. A 6, 5276-5289 (2018).

15. Thomas, C. I. et al. Phase stability control of interstitial oxide ion conductivity in the $\mathrm{La}_{1+x} \mathrm{Sr}_{1-x} \mathrm{Ga}_{3} \mathrm{O}_{7+x / 2}$ melilite family. Chem. Mater. 22, 2510-2516 (2010).

16. Kuang, X., Payne, J. L., Johnson, M. R. \& Evans, I. R. Remarkably High oxide ion conductivity at low temperature in an ordered fluorite-type superstructure. Angew. Chem. Int. Ed. 51, 690-694 (2012).

17. Kuang, X., Payne, J. L., Farrell, J. D., Johnson, M. R. \& Evans, I. R. Polymorphism and oxide ion migration pathways in fluorite-type bismuth vanadate, $\mathrm{Bi}_{46} \mathrm{~V}_{8} \mathrm{O}_{89}$. Chem. Mater. 24, 2162-2167 (2012).

18. Bierlein, J. D. \& Sleight, A. W. Ferroelasticity in $\mathrm{BiVO}_{4}$. Solid State Commun. 16, 69-70 (1975)

19. Hirota, K., Komatsu, G., Yamashita, M., Takemura, H. \& Yamaguchi, O. Formation, characterization and sintering of alkoxy-derived bismuth vanadate. Mater. Res. Bull. 27, 823-830 (1992).
20. Beg, S., Haneef, S. \& Al-Areqi, N. A. S. Study of electrical conductivity and phase transition in $\mathrm{Bi}_{2} \mathrm{O}_{3}-\mathrm{V}_{2} \mathrm{O}_{5}$ system. Phase Transit. 83, 1114-1125 (2010).

21. Malathi, A., Madhavan, J., Ashokkumar, M. \& Arunachalam, P. A review on $\mathrm{BiVO}_{4}$ photocatalyst: activity enhancement methods for solar photocatalytic applications. Appl. Catal. A 555, 47-74 (2018).

22. Kim, T. W. \& Choi, K.-S. Nanoporous $\mathrm{BiVO}_{4}$ photoanodes with dual-layer oxygen evolution catalysts for solar water splitting. Science 343, 990-994 (2014).

23. Esaka, T., Minaai, T. \& Iwahara, H. Oxide ion conduction in the solid-solution based on the scheelite-type oxide $\mathrm{PbWO}_{4}$. Solid State Ion 57, 319-325 (1992).

24. Packer, R. J. \& Skinner, S. J. Remarkable oxide ion conductivity observed at low temperatures in a complex superstructured oxide. Adv. Mater. 22, 1613-1616 (2010).

25. Shannon, R. Revised effective ionic radii and systematic studies of interatomic distances in halides and chalcogenides. Acta Crystallogr. Sect. A 32, 751-767 (1976).

26. Huang, J. \& Sleight, A. W. A new bismuth strontium vanadate, $\mathrm{BiSr}_{2} \mathrm{~V}_{3} \mathrm{O}_{11}$, with both orthovanadate and pyrovanadate groups. J. Solid State Chem. 97, 228-232 (1992).

27. Liu, J.-C., Chen, J.-P. \& Li, D.-Y. Crystal structrue and optical observations of $\mathrm{BiVO}_{4}$. Acta Phys. Sin. 32, 1053-1060 (1983).

28. Sears, V. F. Neutron scattering lengths and cross sections. Neutron News 3 , 26-37 (1992)

29. Lapina, O. B., Mastikhin, V. M., Shubin, A. A., Krasilnikov, V. N. \& Zamaraev, K. I. ${ }^{51} \mathrm{~V}$ solid-state NMR-studies of vanadia based catalysts. Prog. Nucl. Magn. Reson. Spectrosc. 24, 457-525 (1992).

30. Skibsted, J., Jacobsen, C. J. H. \& Jakobsen, H. J. ${ }^{51} \mathrm{~V}$ chemical shielding and quadrupole coupling in ortho- and metavanadates from ${ }^{51} \mathrm{~V}$ MAS NR4R spectroscopy. Inorg. Chem. 37, 3083-3092 (1998).

31. Nielsen, U. G., Jakobsen, H. J. \& Skibsted, J. ${ }^{51}$ V MAS NMR investigation of ${ }^{51} \mathrm{~V}$ quadrupole coupling and chemical shift anisotropy in divalent metal pyrovanadates. J. Phys. Chem. B 105, 420-429 (2001).

32. Pickard, C. J. \& Mauri, F. All-electron magnetic response with pseudopotentials: NMR chemical shifts. Phys. Rev. B 63, 245101 (2001).

33. Profeta, M., Mauri, F. \& Pickard, C. J. Accurate first principles prediction of ${ }^{17} \mathrm{O}$ NMR parameters in $\mathrm{SiO}_{2}$ : assignment of the zeolite ferrierite spectrum. J. Am. Chem. Soc. 125, 541-548 (2003).

34. Charpentier, T. The PAW/GIPAW approach for computing NMR parameters: a new dimension added to NMR study of solids. Solid. State Nucl. Magn. Reson. 40, 1-20 (2011).

35. Bonhomme, C. et al. First-principles calculation of NMR parameters using the gauge including projector augmented wave method: a chemist's point of view. Chem. Rev. 112, 5733-5779 (2012).

36. Irvine, J. T. S., Sinclair, D. C. \& West, A. R. Electroceramics: characterization by impedance spectroscopy. Adv. Mater. 2, 132-138 (1990).

37. Morrison, F. D., Sinclair, D. C. \& West, A. R. Characterization of lanthanumdoped barium titanate ceramics using impedance spectroscopy. J. Am. Ceram Soc. 84, 531-538 (2001).

38. Li, M. et al. A family of oxide ion conductors based on the ferroelectric perovskite $\mathrm{Na}_{0.5} \mathrm{Bi}_{0.5} \mathrm{TiO}_{3}$. Nat. Mater. 13, 31-35 (2014).

39. Li, M. et al. Dramatic influence of A-site nonstoichiometry on the electrical conductivity and conduction mechanisms in the perovskite oxide $\mathrm{Na}_{0.5} \mathrm{Bi}_{0.5} \mathrm{TiO}_{3}$. Chem. Mater. 27, 629-634 (2015).

40. Sinclair, C. D. et al. $\mathrm{NaBi}_{3} \mathrm{~V}_{2} \mathrm{O}_{10}$ : A New Oxide Ion Conductor. J. Mater. Chem. 8, 281-282 (1998).

41. Yang, F. et al. Defect chemistry and electrical properties of sodium bismuth titanate perovskite. J. Mater. Chem. A 6, 5243-5254 (2018).

42. Catlow, C. R. A. Transport in doped fluorite oxides. Solid State Ion. 12, 67-73 (1984).

43. Boivin, J. C. \& Mairesse, G. Recent material developments in fast oxide ion conductors. Chem. Mater. 10, 2870-2888 (1998).

44. Abram, E. J., Sinclair, D. C. \& West, A. R. A novel enhancement of ionic conductivity in the cation-deficient apatite $\mathrm{La}_{9.33}\left(\mathrm{SiO}_{4}\right)_{6} \mathrm{O}_{2}$. J. Mater. Chem. 11, 1978-1979 (2001).

45. Winborne, D. A., Nordine, P. C., Rosner, D. E. \& Marley, N. F. Aerodynamic levitation technique for containerless high temperature studies on liquid and solid samples. Metall. Trans. B 7, 711-713 (1976).

46. Allix, M. et al. Highly transparent $\mathrm{BaAl}_{4} \mathrm{O}_{7}$ polycrystalline ceramic obtained by full crystallization from glass. Adv. Mater. 24, 5570-5575 (2012).

47. Glorieux, B., Saboungi, M. L., Millot, F., Enderby, J. \& Rifflet, J. C. in Space Technology and Applications International Forum (ed. ElGenk, M. S.) 316-324 (American Institute of Physics, New York, 2001).

48. Coelho, A. Topas Academic Version 5 http://www.topas-academic.net/ (2012)

49. Petrícek, V., Dušek, M. \& Palatinus, L. Crystallographic computing system JANA2006: general features. Z. Krist. 229, 345-352 (2014).

50. Fenzke, D., Freude, D., Fröhlich, T. \& Haase, J. NMR intensity measurements of half-integer quadrupole nuclei. Chem. Phys. Lett. 111, 171-175 (1984).

51. Amoureux, J. P., Fernandez, C. \& Steuernagel, S. Z. Filtering in MQMAS NMR. J. Magn. Reson. Ser. A 123, 116-118 (1996). 
52. Skibsted, J., Nielsen, N. C., Bildsoe, H. \& Jakobsen, H. J. Magnitudes and relative orientation of ${ }^{51} \mathrm{~V}$ quadrupole coupling and anisotropic shielding tensors in metavanadates and $\mathrm{KV}_{3} \mathrm{O}_{8}$ from ${ }^{51} \mathrm{~V}$ MAS NMR spectra. ${ }^{23} \mathrm{Na}$ quadrupole coupling parameters for $\alpha$ - and $\beta-\mathrm{NaVO}_{3}$. J. Am. Chem. Soc. 115, 7351-7362 (1993).

53. Jakobsen, H. J., Skibsted, J., Bildsøe, H. \& Nielsen, N. C. Magic-angle spinning NMR spectra of satellite transitions for quadrupolar nuclei in solids. J. Magn. Reson. 85, 173-180 (1989).

54. Massiot, D., Bessada, C., Coutures, J. P. \& Taulelle, F. A quantitative study of ${ }^{27}$ Al MAS NMR in crystalline YAG. J. Magn. Reson. 90, 231-242 (1990).

55. Massiot, D. et al. Modelling one- and two-dimensional solid-state NMR spectra. Magn. Reson. Chem. 40, 70-76 (2002).

56. Johnson, D. Zview for Windows, Impedance/Gain Phase Graphing and Analysis Software (Scribner Associates, North Carolina, 2001).

57. Jing, X. P. \& Rwest, A. A. C. Impedance and gas concentration cell measurements for $\mathrm{Ba}_{12} \mathrm{Y}_{4.67} \mathrm{Ti}_{8} \mathrm{O}_{35}$. Acta Phys. Chim. Sin. 18, 617-623 (2002).

58. Clark, S. J. et al. First principles methods using CASTEP. Z. Krist. 220, 567-570 (2005).

59. Perdew, J. P., Burke, K. \& Ernzerhof, M. Generalized gradient approximation made simple. Phys. Rev. Lett. 77, 3865-3868 (1996).

60. Yates, J. R., Pickard, C. J. \& Mauri, F. Calculation of NMR chemical shifts for extended systems using ultrasoft pseudopotentials. Phys. Rev. B 76, 024401 (2007).

61. Islam, M. S. Ionic transport in $\mathrm{ABO}_{3}$ perovskite oxides: a computer modelling tour. J. Mater. Chem. 10, 1027-1038 (2000).

62. Gale, J. D. GULP: a computer program for the symmetry-adapted simulation of solids. J. Chem. Soc. Faraday Trans. 93, 629-637 (1997).

63. Dick, B. G. Jr. \& Overhauser, A. W. Theory of the dielectric constants of alkali halide crystals. Phys. Rev. 112, 90-103 (1958).

64. Abrahams, I. et al. A combined total scattering and simulation approach to analyzing defect structure in $\mathrm{Bi}_{3} \mathrm{YO}_{6}$. Chem. Mater. 22, 4435-4445 (2010).

65. Lewis, G. V. \& Catlow, C. R. A. Potential models for ionic oxides. J. Phys. C 18, 1149-1161 (1985).

66. Santos, B. F. D., Araujo, R. M., Valerio, M. E. G. \& Rezende, M. V. D. S. Optical spectroscopy study of $\mathrm{YVO}_{4}: \mathrm{Eu}^{3+}$ nanopowders prepared by the proteic sol-gel route. Solid State Sci. 42, 45-51 (2015).

67. Todorov, I. T., Smith, W., Trachenko, K. \& Dove, M. T. DL_POLY_3: new dimensions in molecular dynamics simulations via massive parallelism. $J$. Mater. Chem. 16, 1911-1918 (2006).

68. Humphrey, W., Dalke, A. \& Schulten, K. VMD: visual molecular dynamics. J. Mol. Graph. Model. 14, 33-38 (1996).

69. Rog, T., Murzyn, K., Hinsen, K. \& Kneller, G. R. nMoldyn: a program package for a neutron scattering oriented analysis of molecular dynamics simulations. J. Comput. Chem. 24, 657-667 (2003).

\section{Acknowledgements}

National Natural Science Foundation of China (Nos. 21622101, 21511130134,

21101174), NSFC-CNRS bilateral TransElectro project (No. PICS07091), Guangxi Nat- ural Science Foundation (No. 2014GXNSFGA118004), the Research Project (No. 213030A) of Chinese Ministry of Education, Program for New Century Excellent Talents in University (No. NCET-13-0752), and TGIR-RMN-THC FR3050 CNRS are acknowledged for the financial support. DFT computations have been performed at the "Centre de Calcul Scientifique en Région Centre" facility (CCRS-Orléans, France) under the CASCIMODOT program. We are grateful to Dr. Maria Diaz-Lopez from the ISIS Facility, STFC Rutherford Appleton Laboratory for the constructive comments and English language improvement to this manuscript and to Prof. Yawen Zhang from Peking University for the valuable discussion on correlation between defect chemistry and photocatalytic activity of $\mathrm{BiVO}_{4}$.

\section{Author contributions}

X.K. and M.A. conceived and designed the project. X.Y. and A.J.F.-C. synthesized the materials and carried out the electrical and structural characterization. J.W. performed the static lattice and molecular dynamic simulations. F.F. performed the NMR experiments and DFT calculation and F.P. collected neutron diffraction data. All authors participated into the data analysis, discussed the results, and took part in producing the manuscript.

\section{Additional information}

Supplementary Information accompanies this paper at https://doi.org/10.1038/s41467018-06911-w.

Competing interests: The authors declare no competing interests.

Reprints and permission information is available online at http://npg.nature.com/ reprintsandpermissions/

Publisher's note: Springer Nature remains neutral with regard to jurisdictional claims in published maps and institutional affiliations.

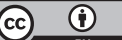

Open Access This article is licensed under a Creative Commons Attribution 4.0 International License, which permits use, sharing, adaptation, distribution and reproduction in any medium or format, as long as you give appropriate credit to the original author(s) and the source, provide a link to the Creative Commons license, and indicate if changes were made. The images or other third party material in this article are included in the article's Creative Commons license, unless indicated otherwise in a credit line to the material. If material is not included in the article's Creative Commons license and your intended use is not permitted by statutory regulation or exceeds the permitted use, you will need to obtain permission directly from the copyright holder. To view a copy of this license, visit http://creativecommons.org/ licenses/by/4.0/.

(c) The Author(s) 2018 